\title{
Temporally precise single-cell-resolution optogenetics
}

\author{
Or A. Shemesh ${ }^{1,2,3,4,5}$, Dimitrii Tanese ${ }^{6}$, Valeria Zampini ${ }^{6,7}$, Changyang Linghu ${ }^{1,2,3,4,5}$, Kiryl Piatkevich ${ }^{1,2,3,4,5}$, \\ Emiliano Ronzitti ${ }^{6,7}$, Eirini Papagiakoumou ${ }^{6,8}$, Edward S. Boyden ${ }^{1,2,3,4,5 \star}$ and Valentina Emiliani ${ }^{6 \star}{ }^{6 \star}$
}

\begin{abstract}
Optogenetic control of individual neurons with high temporal precision within intact mammalian brain circuitry would enable powerful explorations of how neural circuits operate. Two-photon computer-generated holography enables precise sculpting of light and could in principle enable simultaneous illumination of many neurons in a network, with the requisite temporal precision to simulate accurate neural codes. We designed a high-efficacy soma-targeted opsin, finding that fusing the $\mathbf{N}$-terminal $\mathbf{1 5 0}$ residues of kainate receptor subunit 2 (KA2) to the recently discovered high-photocurrent channelrhodopsin CoChR restricted expression of this opsin primarily to the cell body of mammalian cortical neurons. In combination with two-photon holographic stimulation, we found that this somatic CoChR (soCoChR) enabled photostimulation of individual cells in mouse cortical brain slices with single-cell resolution and $<1$-ms temporal precision. We used soCoChR to perform connectivity mapping on intact cortical circuits.
\end{abstract}

Optogenetics is in widespread use for the activation and silencing of populations of neurons defined by their molecular profiles, activity patterns or projection patterns ${ }^{1}$. Natural neural codes, however, vary from neuron to neuron even within a single class of cells, with neighboring neurons of the same type exhibiting potentially highly differing neural codes ${ }^{2}$ and the firing of even single neurons capable of altering mammalian behavior or brain state ${ }^{3,4}$. Thus, an intriguing question is whether it is possible to drive individual neurons or sets of neurons with neuron-specific, distributed activity patterns exhibiting the temporal precision requisite to mimic natural neural codes.

Recently, interest has arisen around the topic of two-photon (2P) optogenetics, which as a result of the quadratic dependence of $2 \mathrm{P}$ excitation on light intensity and of the low scattering of infrared wavelengths, enables light to be targeted to single neurons at depth. $2 \mathrm{P}$ activation of opsins is robust at a biophysical level, with an excellent cross section for opsin photoactivation ${ }^{5}$, but it is challenging to generate enough photo-evoked current using the micrometer-sized excitation volume of conventional $2 \mathrm{P}$ microscopy. Two primary strategies have been developed to increase the $2 \mathrm{P}$ illumination volume while keeping micrometer axial resolution: scanning and parallel. Scanning a laser spot, axially elongated to cover cell membranes, around a circular area with approximately the diameter of a cell body enables sequential excitation of channels, each contributing to the total induced photocurrent ${ }^{5}$. Scanning approaches, however, have limited temporal resolution because of the time needed to sequentially scan the laser through multiple positions to cover a single cell body or multiple cells ${ }^{6}$.

Parallel stimulation approaches such as generalized phase contrast $^{7}$ or computer-generated holography $(\mathrm{CGH})^{8}$ use phase modulation to precisely sculpt the illumination volume and simultaneously illuminate an entire cell or even multiple cells. In this case, simultaneous illumination of all channels enables efficient integration of light-evoked currents, allowing minimization of illumination time. In this condition action potentials can be generated with millisecond temporal resolution ${ }^{7,9}$ and submillisecond temporal jitter ${ }^{10,11}$. Combined with temporal focusing, parallel stimulation also enables micrometer axial resolution and good preservation of axial resolution and spot shape after hundreds of micrometers of light propagation in scattering tissues ${ }^{9,12,13}$. CGH also enables 3D light generation ${ }^{12,14-16}$, laying the groundwork for generating complex patterns with single-cell spatial resolution and millisecond temporal precision.

Advances in 2P stimulation methods, however, do not directly address the problem of cell bodies being densely surrounded by neurites of neighboring cells, whose membranes are separated by very thin gaps of extracellular space, smaller than the diffraction limit of light ${ }^{17}$. Thus, if neurons within a region bear densely expressed opsins, even 2P stimulation of a single neuron's cell body may excite opsins on dendrites or axons that are passing by, causing stray excitation of those nearby neurons. To address this crosstalk problem (Fig. 1a), we launched a screen to discover peptide sequences that could facilitate the localization of a highphotocurrent opsin to the cell body. We found that a short aminoterminal segment of the kainate receptor KA2 subunit ${ }^{18}$, fused to the high-photocurrent channelrhodopsin $\mathrm{CoChR}^{19}$, could enable the selective trafficking of CoChR to the cell body of neurons in the mammalian cortex (Fig. 1b), and, in combination with holographic $2 \mathrm{P}$ stimulation with a low-repetition fiber laser, this construct could support optogenetic stimulation of single cells in mammalian brain slices with $<1$-ms temporal resolution and with zero-spike crosstalk activation of nearby cells, using delivery of pulses of light of modest light powers. This fusion protein, which we call somatic CoChR (soCoChR), used in conjunction with optimized 2P stimulation approaches, may enable a diverse set of neural codes and computations to be probed in a causal fashion in systems and circuit neuroscience.

'Media Laboratory, Massachusetts Institute of Technology (MIT), Cambridge, MA, USA. ${ }^{2}$ Department of Biological Engineering, MIT, Cambridge, MA, USA. ${ }^{3}$ Center for Neurobiological Engineering, MIT, Cambridge, MA, USA. ${ }^{4}$ Department of Brain and Cognitive Sciences, MIT, Cambridge, MA, USA. ${ }^{5} \mathrm{McGovern}$ Institute for Brain Research, MIT, Cambridge, MA, USA. ${ }^{6}$ Neurophotonics Laboratory, Wave Front Engineering Microscopy Group, CNRS UMR8250, Université Paris Descartes, Paris, France. ${ }^{7}$ Institut de la Vision, UM 80, UPMC, Paris, France. ${ }^{8}$ Institut national de la santé et de la recherche médicale (Inserm), Paris, France. Or A. Shemesh, Dimitrii Tanese and Valeria Zampini contributed equally to this work. ${ }^{*}$ e-mail: esb@media.mit.edu; valentina.emiliani@parisdescartes.fr 


\section{Results}

Creation of a high-performance somatic opsin. We screened for soma-targeting sequences that could localize high-performance opsins to neuronal cell bodies. We first searched the literature for proteins that express somatically. We chose nine such proteins for consideration (Supplementary Table 1): myelin proteolipid proteins srPLP and

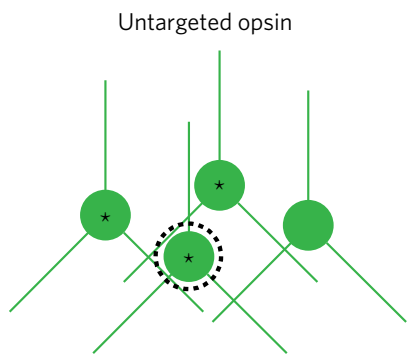

b Soma-targeted opsin

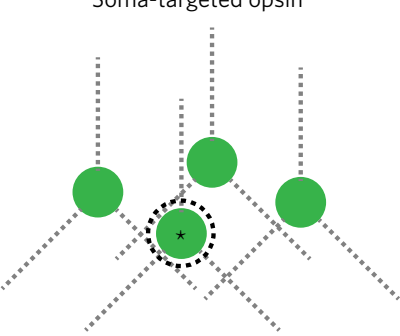

$\because$ Cell targeted by light

$\star \quad$ Excited cell

Opsin-bearing soma

Opsin-bearing neurite

Non-opsin-bearing neurite

Opsin-GFP
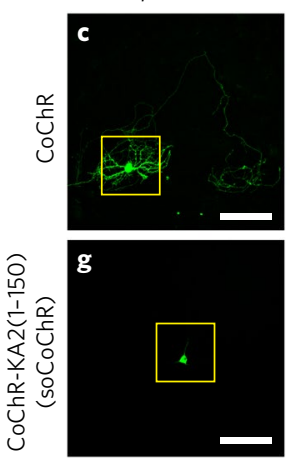

Zoom-in of opsin-GFP
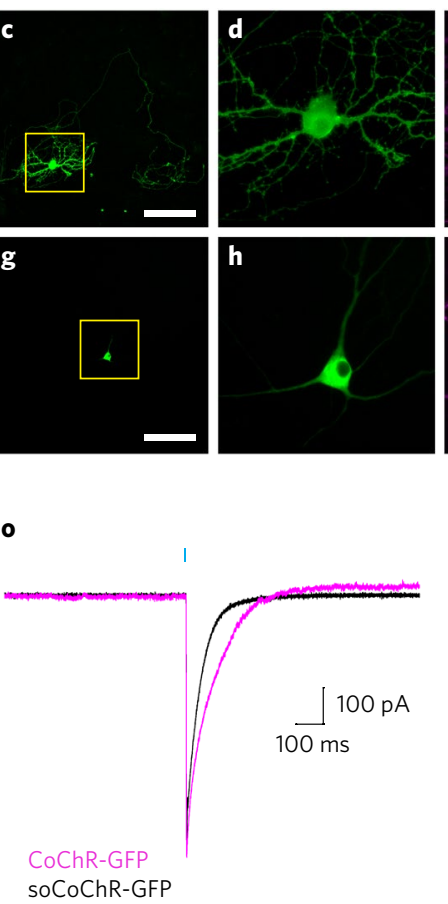

mCherry
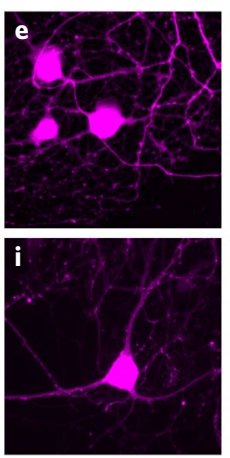

$\mathbf{p}$
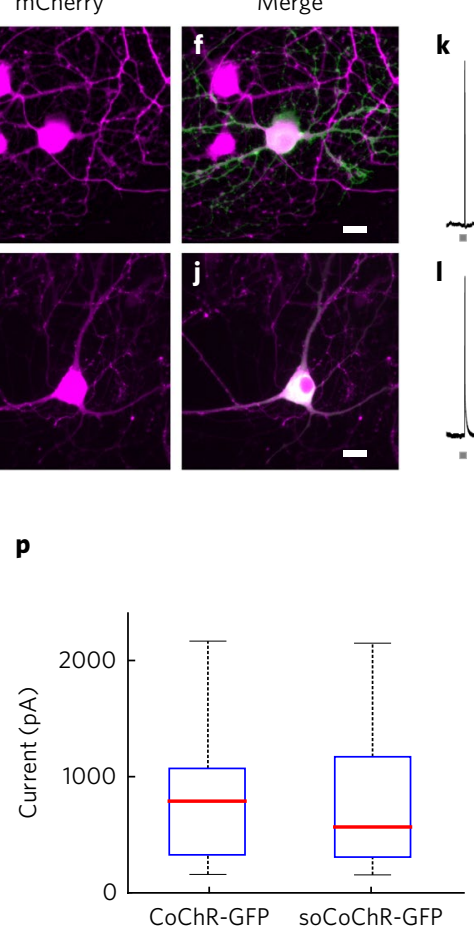
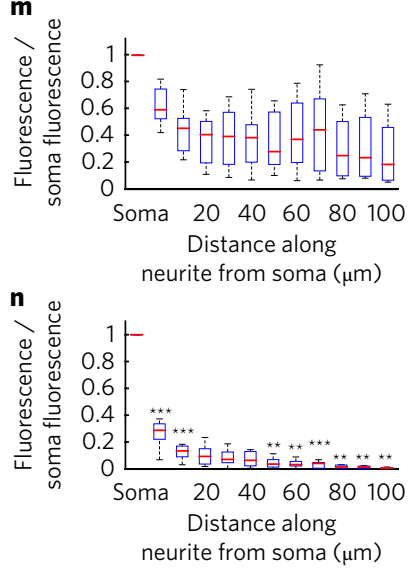
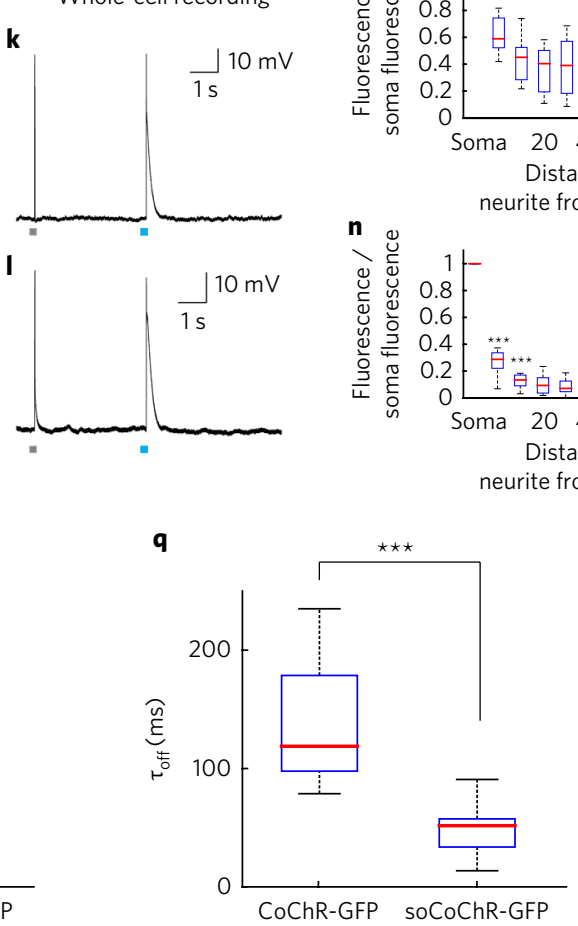

Fig. 1 | Soma-targeted optogenetics using the high-performance channelrhodopsin CoChR. a,b, Concept of soma-targeted optogenetics. Untargeted opsins, shown in $\mathbf{a}$, express over the entire neural membrane. One can aim light at a given neural soma, but each cell body is surrounded by opsin-bearing neurites from other cells, resulting in artifactual activation of those cells. Restricting opsin expression to the cell body would prevent such side effects, enabling singlecell optogenetic stimulation, shown in $\mathbf{b}$. c-j, Images are presented for cultured hippocampal neurons expressing wild-type vs. selectively trafficked CoChR fused to GFP, along with the cytosolic countermarker mCherry. c, A hippocampal neuron in culture expressing CoChR-GFP and mCherry, seen in the GFP channel (scale bar: $100 \mu \mathrm{m}$ ). d, Enlarged image from the yellow rectangle of $\mathbf{c}$. $\mathbf{e}$, The neuron from c, seen in the mCherry channel (magenta), along with surrounding neurons. f, Merge of $\mathbf{d}$ and $\mathbf{e}$ (scale bar for $\mathbf{d}-\mathbf{f}$ : $20 \mu \mathrm{m}$ ). $\mathbf{g - j}$ - , As in c-f, but for a neuron expressing CoChR-KA2(1-150)-GFP (soCoChR-GFP). k. Whole-cell current clamp recording of a cultured hippocampal neuron expressing CoChR-GFP, under current injection (10 ms duration; gray rectangle) and optical stimulation ( $480 \mathrm{~nm}, 34.84 \mathrm{~mW} / \mathrm{mm}^{2}, 1 \mathrm{~ms}$ duration; blue rectangle). Rectangles not to scale. I, As in $\mathbf{k}$, but for a neuron expressing soCoChR-GFP. $\mathbf{m}$, Box-and-whiskers plot of GFP brightness versus position along a neurite, normalized to GFP brightness at the soma, extracted from neurites of cultured hippocampal neurons expressing CoChR-GFP ( $n=7$ neurites taken from 5 cells from 2 cultures). Red line denotes the median. Top and bottom edges of the box indicate the 75th and 25th percentiles, respectively. Top and bottom whiskers indicate the highest and lowest values, respectively. $\mathbf{n}$, As in $\mathbf{m}$, but for neurons expressing soCoChR-GFP ( $n=9$ neurites taken from 7 cells from 3 cultures). ${ }^{\star \star} P<0.01$ and ${ }^{* \star \star} P<0.001$, Bonferroni-corrected Kolmogorov-Smirnov test of brightness between wild-type and soma-targeted; see Supplementary Table 3 for full statistics). o, Representative photocurrents for cultured hippocampal neurons expressing CoChR-GFP (magenta) and soCoChR-GFP (black), under voltage clamp conditions, using 5-ms light pulses $\left(480 \mathrm{~nm}, 34.84 \mathrm{~mW} / \mathrm{mm}^{2}\right.$; light blue rectangle). p, Box-and-whiskers plot (presented as in $\mathbf{m}$ ) showing peak current amplitudes ( $\mathrm{pA}$ ) for CoChR-GFP and soCoChR-GFP in cultured hippocampal neurons illuminated with blue light $\left(480 \mathrm{~nm}, 34.84 \mathrm{~mW} / \mathrm{mm}^{2}, 5 \mathrm{~ms} ; n=13\right.$ neurons from 3 cultures and 13 neurons from 3 cultures for CoChR-GFP and soCoChR-GFP, respectively). Not significant; $P=0.6444$; Wilcoxon rank sum test; see Supplementary Table 3 for full statistics. q, Box-and-whiskers plot (presented as in $\mathbf{m}$ ) showing photocurrent decay time ( $\tau_{\text {off }}$ in milliseconds) for CoChR-GFP and soCoChR-GFP in cultured hippocampal neurons illuminated with blue light $\left(480 \mathrm{~nm}, 34.84 \mathrm{~mW} / \mathrm{mm}^{2}, 5 \mathrm{~ms} ; n=13\right.$ neurons from 3 cultures and 13 neurons from 3 cultures for CoChRGFP and soCoChR-GFP, respectively). ${ }^{\star \star \star} P<0.0001$; Wilcoxon rank sum test; see Supplementary Table 3 for full statistics. 
$\mathrm{DM} 20^{20}$, the potassium channel $\mathrm{K}_{\mathrm{V}} 2.1^{21}$, sodium channels $\mathrm{Na}_{\mathrm{V}} 1.2$ and $\mathrm{Na}_{\mathrm{V}} 1.6^{22}$, the adhesion molecule L1 with the soma-retention-causing mutation $\mathrm{R} 184 \mathrm{Q}^{23}$, the dynein adaptor protein Bicaudal-D (BicD) truncated after 50 codons (out of 782; this truncation impairs transport of fragile X mental retardation protein out of the soma $)^{24,25}$, the adaptor protein ankyrin $\mathrm{G}^{26}$ and the kainate receptor subunit $\mathrm{KA} 2^{18}$. a Untargeted opsin

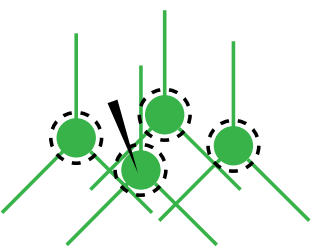

b Soma-targeted opsin

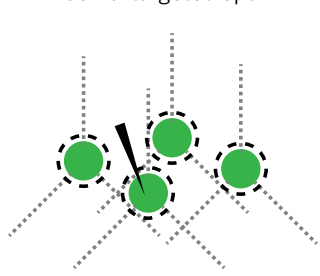

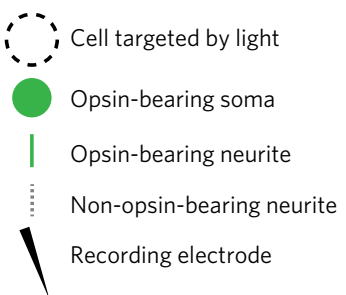

; Cell targeted by light

Opsin-bearing neurit
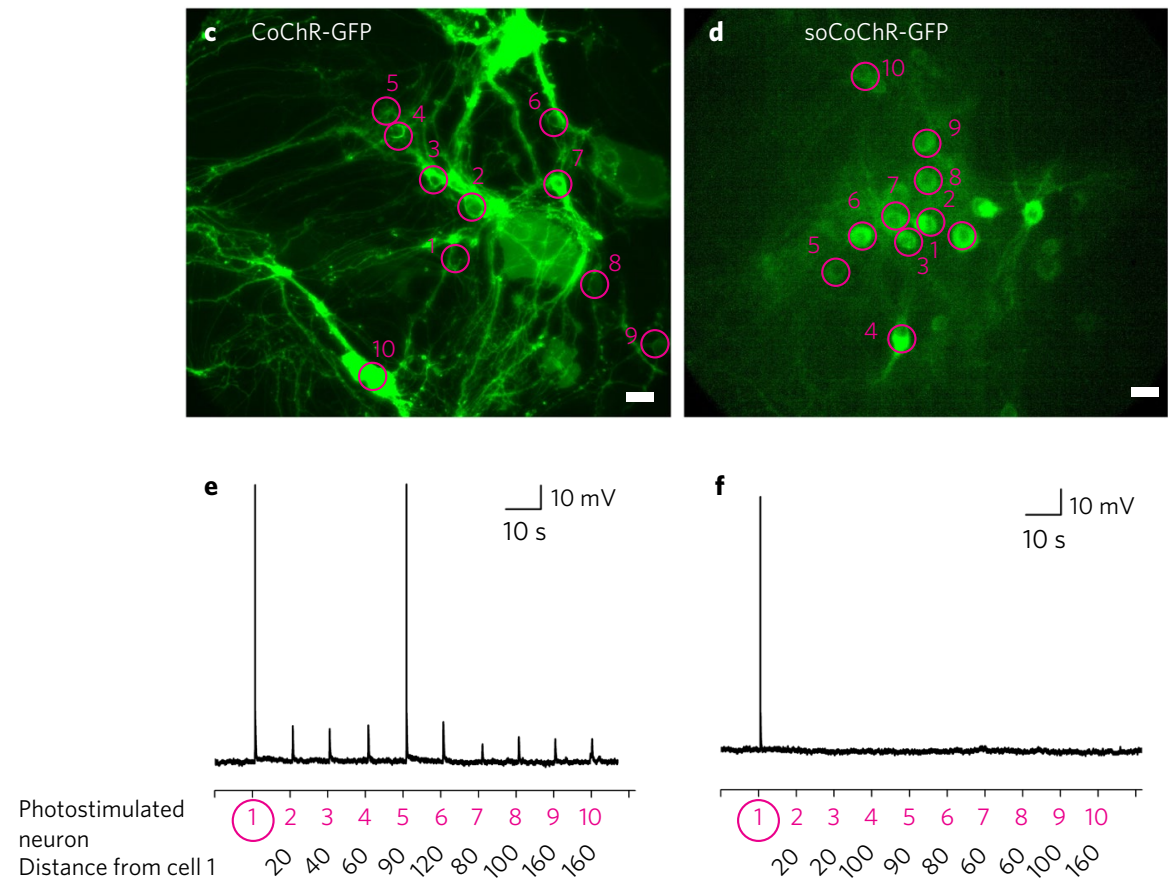

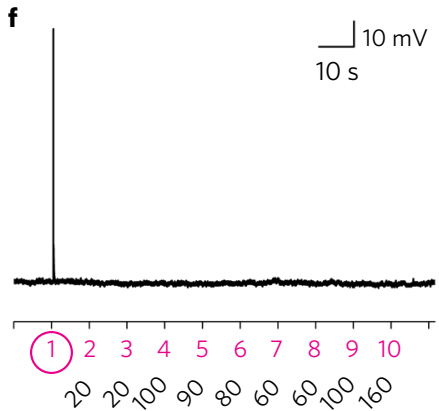


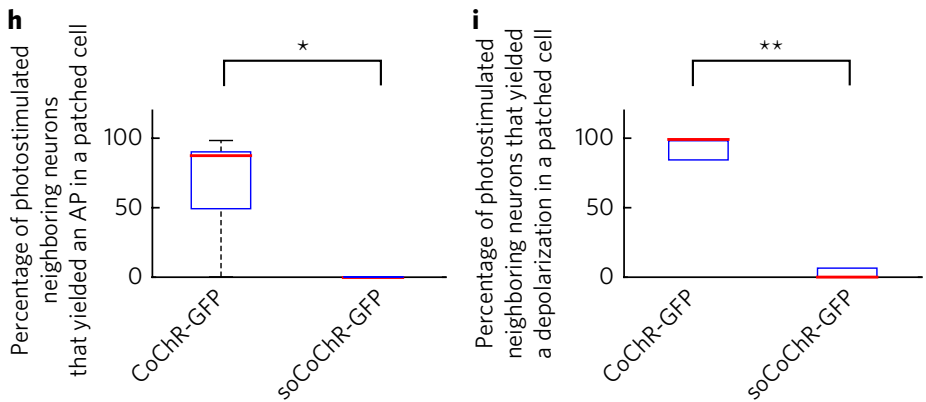

Fig. 2 | Zero-spike crosstalk single-cell optogenetic control of cultured neurons with 1P illumination. a,b, Schematic of the experiment. Cultured hippocampal neurons 2 weeks after transduction with AAV8-Syn-CoChR-GFP (untargeted CoChR, a) or AAV8-Syn-soCoChR-GFP (somatic soCoChR, b). One cell in the field of view was patched (current clamp). The patched cell along with nine neighboring cells were photostimulated consecutively using a digital micromirror device (DMD). c, Cultured hippocampal neurons expressing CoChR-GFP; regions of stimulation are highlighted by magenta circles. Numbers denote the order of stimulation. Scale bar: $20 \mu \mathrm{m}$. d, As in c, but for soCoChR-GFP. e, Representative current-clamp recording for a cultured hippocampal neuron expressing CoChR-GFP. Cells were photostimulated sequentially using the DMD ( $470 \mathrm{~nm}, 40.7 \mathrm{~mW} / \mathrm{mm}^{2}, 1 \mathrm{~ms}$ light pulse). The order of photostimulation, as indicated by the numbers in $\mathbf{c}$, is given on the $x$ axis. The patched cell is numbered 1. The distance of cells $2-9$ from the patched cell is given below each cell number in micrometers. $\mathbf{f}$, As in $\mathbf{e}$, but for soCoChR-GFP. g, Percentage of cultured hippocampal neurons that fired an AP upon direct photostimulation, using light pulses as above ( $n=5$ cells from 4 cultures for CoChR-GFP; $n=5$ cells from 5 cultures for soCoChR-GFP). Red line denotes the median. $\mathbf{h}$, Box-and-whiskers plot showing, averaged across all patched neurons, the percentage of photostimulated neighboring cells that yielded an AP in each patched cell ( $n=5$ cells from 4 cultures for CoChR-GFP; $n=5$ cells from 5 cultures for soCoChR-GFP). Red line denotes the median. Top and bottom edges of the box indicate the 75th and 25th percentiles, respectively. Top and bottom whiskers indicate the highest and lowest values, respectively. ${ }^{\star} P=0.0476$, Wilcoxon rank sum test; see Supplementary Table 3 for full statistics. i, Box-and-whiskers plot (presented as in $\mathbf{h}$ ) showing, averaged across all patched neurons, the percentage of photostimulated neighboring cells that yielded a depolarization in each patched cell $(n=5$ cells, in 4 cultures for CoChR-GFP; $n=5$ cells, in 5 cultures for soCoChR-GFP). ${ }^{\star \star} P=0.0079$, Wilcoxon rank sum test; see Supplementary Table 3 for full statistics. 


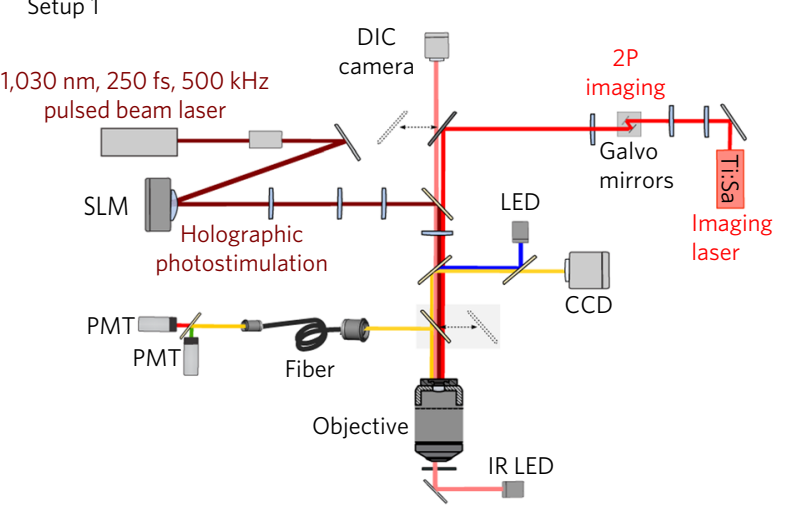
Setup 2

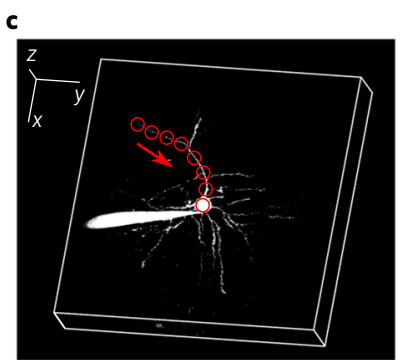

d
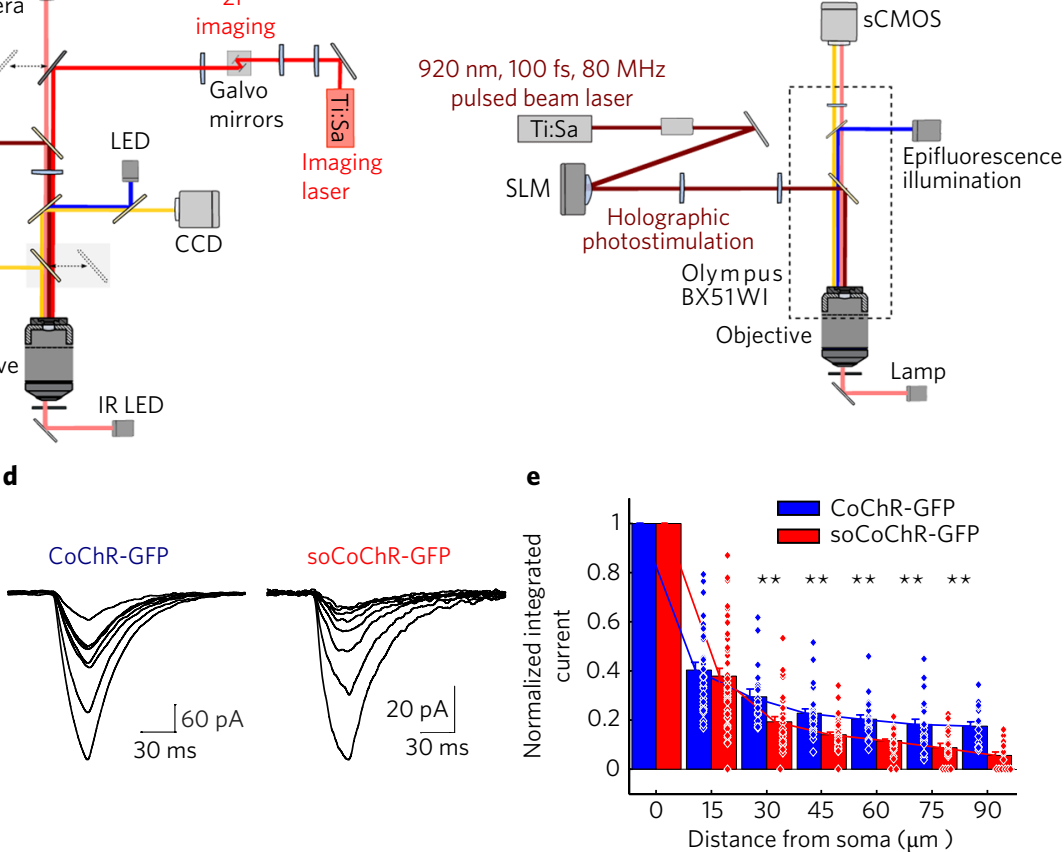

Fig. 3 | Photocurrents of neurites expressing soCoChR-GFP are significantly smaller than in neurites expressing CoChR-GFP, in neurons virally expressing these opsins in mouse cortical brain slices. $\mathbf{a}, \mathbf{b}$, Schematic representation of the two experimental setups used for holographic illumination. In setup 1, shown in a, holographic photostimulation was achieved using an amplified fiber laser and was coupled with a two-photon (2P) scanning imaging system. In setup 2, shown in $\mathbf{b}$, holographic photostimulation was achieved using a conventional Ti:sapphire pulsed laser and was coupled with a widefield epifluorescence imaging system. See Methods and Supplementary Fig. 6. CCD, charge-coupled device; DIC, differential interference contrast; galvo, galvanometer; IR LED, infrared light-emitting diode; PMT, photomultiplier tube; sCMOS, scientific complementary metal-oxide semiconductor camera; SLM, spatial light modulator; Ti:Sa, titanium-sapphire laser. c, Schematic of 2P holographic stimulation along one neurite, showing Alexa 594 fluorescence (obtained via $2 \mathrm{P}$ scanning at $780 \mathrm{~nm}$ ) from dye injected into a patched CoChR-GFP-expressing neuron. The Alexa 594 fluorescence was used to guide holographic spot placement (red circles) to different points along a neurite, at different distances from the soma. Red arrow indicates the order of photostimulation. The bright emission to the left of the cell represents the patch pipette filled with Alexa 594 (scale bars: $50 \mu \mathrm{m}$ along all three axes; image acquired with setup 1). d, Representative whole-cell currents recorded from a CoChR-GFP-expressing neuron (left) and a soCoChR-GFPexpressing neuron (right; some $50 \mathrm{~Hz}$ electrical noise is apparent in the traces on the right), illuminated with a power density corresponding to the spiking threshold power density $\left(18 \mu \mathrm{W} / \mu \mathrm{m}^{2}\right.$ and $101 \mu \mathrm{W} / \mu \mathrm{m}^{2}$ for the CoChR-GFP- and the soCoChR-GFP-expressing cells, respectively; $\lambda=1,030 \mathrm{~nm}$; setup 1$)$. e, Bar plot of the integral of the elicited photocurrent, normalized to that obtained with the spot at the soma, as a function of distance from the soma, for CoChR-GFP-expressing (blue bars) and soCoChR-GFP-expressing (red bars) neurons (spacing between spots $\sim 10 \mu \mathrm{m}, \lambda=1,030 \mathrm{~nm}$ or $920 \mathrm{~nm}$ for setup 1 or setup 2, respectively; data were pooled across the two setups). Bars reports mean \pm s.e.m. Dots denote values for single neurites. For each cell, the photostimulation was done at the power density threshold determined for that cell (average powers: $29 \pm 10 \mu \mathrm{W} / \mu \mathrm{m}^{2}$ for CoChR-GFP-expressing cells, $90 \pm 60 \mu \mathrm{W} / \mu \mathrm{m}^{2}$ for soCoChR-GFP-expressing cells; power values refer to setup 1; see Methods). The normalized current integral was significantly higher in CoChR-GFP relative to soCoChR-GFP-expressing cells for distances of $30 \mu \mathrm{m}$ or more from the soma. ${ }^{\star \star} P<0.0017$ for distances $\geq 30 \mu \mathrm{m}$; KolmogorovSmirnov test with Bonferroni correction ( $n=16$ neurites from 8 CoChR-GFP cells from 7 mice; $n=27$ neurites from 16 soCoChR-GFP cells from 13 mice; see Supplementary Table 4 for full statistics).

In some studies, neuron somatic localization had been explored further by fusing the proteins to reporters: $\mathrm{Na}_{\mathrm{v}} 1.2, \mathrm{Na}_{\mathrm{v}} 1.6$, L1-R184Q and ankyrin G had previously been fused to fluorescent proteins ${ }^{22,23,26}$, KA2 to a myc $\operatorname{tag}^{18}$ and $\mathrm{K}_{\mathrm{v}} 2.1$ to a hemagglutinin (HA) $\operatorname{tag}^{21}$. For some of the above soma-restricting proteins, fragments were shown to be sufficient to cause somatic targeting of a reporter (Supplementary Table 1). For each of $\mathrm{Na}_{\mathrm{v}} 1.2$ and $\mathrm{Na}_{\mathrm{v}} 1.6$, a 27-amino-acid segment within the intracellular loop between transmembrane domains II and III-termed $\mathrm{Na}_{\mathrm{v}} 1.2(\mathrm{II}-\mathrm{III})$ and $\mathrm{Na}_{\mathrm{v}} 1.6(\mathrm{II}-\mathrm{III})$, respectively-was sufficient ${ }^{22}$; for $\mathrm{K}_{\mathrm{v}} 2.1$ a 65 -aminoacid segment at the $\mathrm{C}$ terminus (here abbreviated Kv2.1-motif) sufficed $^{21,27}$; for ankyrin $\mathrm{G}$ the $\mathrm{N}$-terminal 837 amino acids of the protein sufficed $^{28}$; and for $\mathrm{BicD}$ the $\mathrm{N}$-terminal 50 amino acids located at locus r5 in the Drosophila BicD gene sufficed ${ }^{25}$.

We fused GFP to full-length clones of the four soma-targeting proteins described above for which no sufficient fragment was reported (srPLP, DM20, L1-R84Q and KA2), as well as to the reported fragments for the other proteins (Supplementary Table 1). We transfected these GFP fusions into cultured hippocampal neurons and visually observed that three of the nine sequences tested appeared to target GFP primarily to the cell body (Supplementary Table 1).

We chose two of these three proteins for further consideration, KA2 and NaV1.2(II-III)-GFP (the third, ankyrin, was too large to easily be delivered in the AAV virus). Since KA2 is a 979-aminoacid protein and thus unwieldy from a viral packaging standpoint, we divided KA2 into three parts. This resulted in fragments (listed from $\mathrm{N}$ terminus to $\mathrm{C}$ terminus) of length 360 amino acids (containing one transmembrane domain ${ }^{29}$ ), 360 amino acids (containing three transmembrane domains) and 259 amino acids (containing one transmembrane domain and an arginine-rich endoplasmic reticulum retention sequence $\left.{ }^{30}\right)$. GFP fused to the first fragment was 


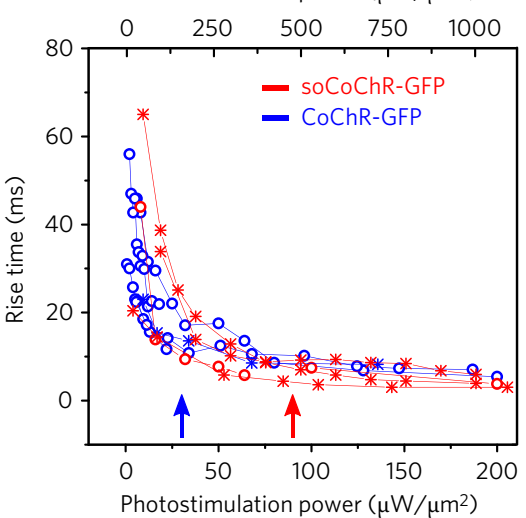

b

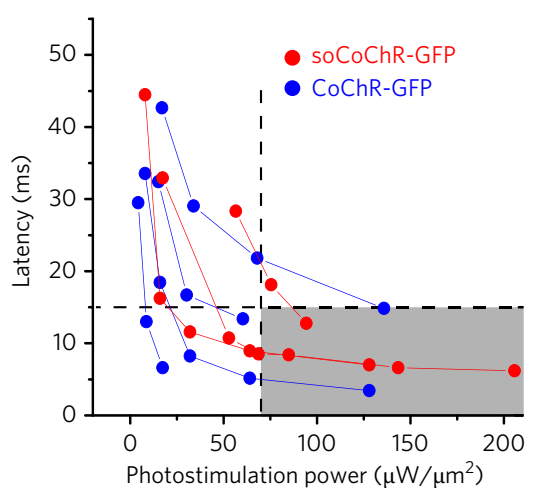

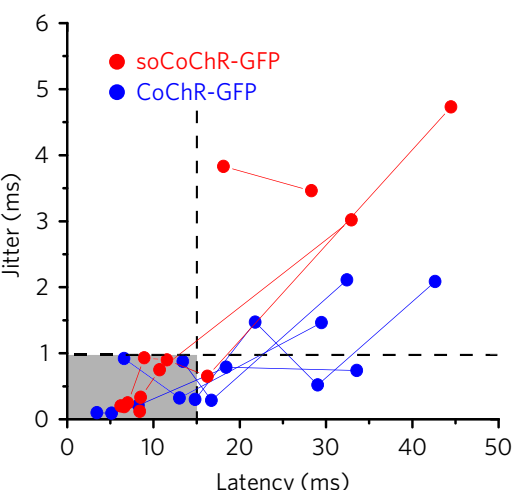

Fig. 4 | 2P power necessary to enable millisecond control of cortical neuron activation in mouse brain slice. a, Rise time of soCoChR-GFP-mediated (red) and CoChR-GFP-mediated (blue) photocurrents, measured in mouse brain slice cortical neurons, as a function of $2 \mathrm{P}$ stimulation power ( $n=4-12$ photostimulation powers per cell, 6 cells from 6 mice for CoChR-GFP; $n=2-11$ photostimulation powers per cell, 5 cells from 5 mice for soCoChR-GFP). Data collected from setup 1 are plotted with circles and correspond to the power scale on the bottom $x$ axis; data collected from setup 2 are plotted with asterisks and correspond to the top $x$ axis. The length of the top $x$ axis was rescaled with respect to the bottom $x$ axis by a power conversion factor $k=5.3$ (see Methods). Lines connect data acquired from the same neuron. Blue and red arrows indicate average threshold powers relative to setup $1 \mathrm{for}$ CoChRGFP- and soCoChR-GFP-expressing neurons, respectively (for CoChR-GFP: $28 \pm 10 \mu \mathrm{W} / \mu \mathrm{m}^{2}, n=7$ cells from $5 \mathrm{mice}$; for soCoChR-GFP: $83 \pm 39 \mu \mathrm{W} / \mu \mathrm{m}^{2}$, $n=4$ cells from 4 mice). b. The AP latency, defined as the time from the onset of $2 P$ stimulation to the peak of the AP, plotted vs. $2 \mathrm{P}$ stimulation power in setup 1 units ( $n=3-5$ powers per cell for 4 cells from 3 mice for CoChR-GFP, blue dots; $n=3-5$ powers per cell for 3 cells from 3 mice for soCoChRGFP, red dots). Lines connect data acquired from the same neuron. Horizontal dashed line denotes $15 \mathrm{~ms}$ latency and vertical dashed line denotes $70 \mu \mathrm{W} / \mu \mathrm{m}^{2}$ stimulation power, for comparison to c. Setups 1 and 2 were used interchangeably; power values used on setup 2 were scaled to equivalent power values for setup 1 (see Methods). See $\mathbf{c}$ for description of the gray area. c, AP temporal jitter (measured as s.d. of the AP latency across a series of 5 photostimulations for a given cell) plotted as a function of AP latency ( $n=3-5$ powers per cell for 4 cells from 3 mice for CoChR-GFP, blue dots; $n=3-5$ powers per cell for 3 cells from 3 mice for soCoChR-GFP, red dots). Lines connect data acquired from the same neuron. Setups 1 and 2 were used interchangeably. Jitter below $1 \mathrm{~ms}$ (horizontal dashed line) was ensured when the latency was kept below $15 \mathrm{~ms}$ (vertical dashed line), corresponding to a photostimulation power higher than $\sim 70 \mu \mathrm{W} / \mu \mathrm{m}^{2}$. The gray areas in $\mathbf{b}$ and $\mathbf{c}$ mark the region in which such conditions were satisfied.

somatic, but GFP fused to the latter two were not (Supplementary Table 1). We tried the N-terminal 150 amino acids of fragment 1 , which we termed KA2(1-150), and found that this targeted GFP to the cell body (Supplementary Fig. 1 and Supplementary Table 2), but KA2(1-75) did not. As for NaV1.2(II-III), an earlier study ${ }^{31}$ using this to target ChR2-YFP to the axon hillock of neurons revealed photocurrents smaller than those of ChR2-YFP ${ }^{31}$, as well as alterations of neuron excitability ${ }^{32}$, so we retained this motif for comparison purposes (Supplementary Fig. 2 and Supplementary Table 3) but did not pursue it further.

Key to efficient use of $2 \mathrm{P}$ light power for multicell activation is the presence of an opsin with high currents. Accordingly, we examined opsins that exhibited very high photocurrents but whose performance in intact mammalian brain circuitry had not yet been explored. We fused KA2(1-150) to the C terminus of CoChR, a powerful opsin with perhaps the largest photocurrent yet described $^{19}$, nearly an order of magnitude bigger than that of ChR2, at least when assessed in cultured neurons. We examined the resulting localization in cultured neurons, finding that, unlike wild-type CoChR-GFP (Fig. 1c-f), CoChR-KA2(1-150)-GFP (here called soma-targeted CoChR or soCoChR for short) appeared primarily at and near the cell body (Fig. $1 \mathrm{~g}-\mathrm{j}$ ). Quantitatively, at $50 \mu \mathrm{m}$ from the edge of the cell body, CoChR-KA2(1-150)-GFP fluorescence was $4.67 \pm 1.29 \%$ of the average brightness across the cell body, in contrast to $35.56 \pm 8.33 \%$ for the wild-type opsin (mean \pm s.e.m.; $n=9$ neurites taken from 7 cells from 3 cultures for the KA2 fusion, $n=7$ neurites taken from 5 cells from 2 cultures for the wild type; Fig. $1 \mathrm{~m}, \mathrm{n})$. We found that, for most distances between 0 and $100 \mu \mathrm{m}$ from the edge of the cell body, in CoChR-KA2(1-150)-GFPexpressing cells the neurite fluorescence was significantly lower than in CoChR-GFP-expressing cells $(n=9$ neurites from 7 cells from 3 cultures for CoChR-KA2(1-150)-GFP; $n=7$ neurites from
5 cells from 2 cultures for CoChR-GFP; see Supplementary Table 3 for statistics).

As for the Kv2.1-motif sequence, which has been used by multiple groups to target ChR2 to the cell body ${ }^{27,33}$, we found that the expression of CoChR-GFP-Kv2.1-motif was not purely at the cell body (Supplementary Fig. 3). Quantitatively, at $50 \mu \mathrm{m}$ from the edge of the cell body, CoChR-GFP-Kv2.1-motif fluorescence was $33.60 \pm 4.75 \%$ of the average brightness across the cell body, whereas this ratio was $35.56 \pm 8.33 \%$ for wild-type CoChR (mean \pm s.e.m.; $n=5$ neurites taken from 5 cells from 2 cultures for the Kv2.1-motif fusion, $n=7$ neurites taken from 5 cells from 2 cultures for the wild type; Supplementary Fig. 3). Statistically, the brightness difference between CoChR-GFP and CoChR-GFP-Kv2.1 was not significant along neurites $(n=5$ neurites from 3 cells from 2 cultures for CoChR-GFP-Kv2.1-motif; $n=7$ neurites from 5 cells from 2 cultures for CoChR-GFP; see Supplementary Table 3 for Bonferroni-corrected Kolmogorov-Smirnov tests). Thus we chose not to further pursue CoChR-GFP-Kv2.1-motif.

CoChR-GFP and CoChR-KA2(1-150)-GFP could both mediate action potentials (APs) in neurons in response to blue light pulses (Fig. 1k,1). Photocurrent measurements (Fig. 1o,p; 5-ms light pulses at $480 \mathrm{~nm}, 34.84 \mathrm{~mW} / \mathrm{mm}^{2}$ ) revealed that CoChR-GFP and CoChRKA2(1-150)-GFP had average photocurrents of 1,029 $\pm 217 \mathrm{pA}$ and $720 \pm 156 \mathrm{pA}$, respectively (mean \pm s.e.m., $n=13$ and 13 cells each from 3 and 3 cultures for CoChR-GFP and CoChR-KA2(1150)-GFP, respectively; Supplementary Table 3). As previously reported $^{19}$, CoChR-GFP under single-photon (1P) widefield activation has a long photocurrent decay time (Fig. 1q; $\tau_{\text {off }}=150 \pm 18 \mathrm{~ms}$, where value is mean \pm s.e.m.). This value was shorter for CoChRKA2(1-150)-GFP (52 \pm 6 ms; mean \pm s.e.m.; $n=13$ neurons from 3 cultures, 13 neurons from 3 cultures for CoChR-GFP and CoChRKA2(1-150)-GFP, respectively; Fig. 1q; see Supplementary Table 3), 
perhaps because in the latter case the patch pipette is not recording the currents that propagate in from distant neurites when a wildtype opsin is illuminated.

Using CoChR- and soCoChR-expressing cultured neurons, we measured the action spectra of these molecules (Supplementary Fig. 4a), the spike probability (Supplementary Fig. 4b) and photocurrent (Supplementary Fig. 4c) mediated by these molecules as a function of irradiance, and the spike fidelity mediated by these molecules as a function of the stimulation frequency (Supplementary Fig. 4d). We also examined basic cell health parameters. The passive membrane properties for neurons containing CoChR-GFP $(n=10$ cells from 3 cultures) vs. CoChR-KA2(1-150)-GFP ( $n=10$ cells from 3 cultures) were not significantly different $(P>0.05$, KruskalWallis test for these membrane properties: resting potential, membrane capacitance, holding current and membrane resistance; see Supplementary Fig. 5).

Somatic CoChR enables single-cell optogenetic control using $1 P$ photostimulation. To test whether soCoChR-GFP could mediate $1 \mathrm{P}$ stimulation of cultured neurons without stimulating nearby cells, we patched a single cell under widefield fluorescence microscopy and used a digital micromirror device (DMD) to photostimulate the patched cell and its neighbors with $20-\mu \mathrm{m}$-diameter spots (Fig. 2a,b) under synaptic blockade. For cells expressing either CoChR-GFP or soCoChR-GFP ( $n=5$ for both opsins; average distance of photostimulated cell from patched cell $=76.89 \pm 6.98 \mu \mathrm{m}$ and $74.22 \pm 6.50 \mu \mathrm{m}$, respectively; Fig. $2 \mathrm{c}, \mathrm{d}$ and Supplementary Table 3), illuminating the cell body of the patched cell as described in Fig. 2e always yielded an AP in that cell. Furthermore, while patching a CoChR-GFP-expressing cell and photostimulating the somata of neighboring (i.e., non-patched) CoChR-GFP-expressing cells, we recorded an AP when photostimulating $62.0 \pm 16.3 \%$ of the neighboring cells (Fig. $2 \mathrm{e}, \mathrm{h}$; mean \pm s.e.m.; $n=5$ patched cells from 4 cultures); in contrast, while patching a soCoChR cell, photostimulating the neighboring cells' somata never resulted in an AP in the patched cell $(P<0.01$, Wilcoxon rank sum test; Fig. $2 \mathrm{f}-\mathrm{h}$; $n=5$ patched cells from 5 cultures). Analyzing the data further, we found depolarizations of $>0.5 \mathrm{mV}$ above baseline (defined as the average voltage over the $100 \mathrm{~ms}$ preceding the voltage change; see Methods) in patched cells within CoChR-GFP-expressing networks when $96.0 \pm 2.4 \%$ of the nearby cells were stimulated (Fig. 2e,i; mean \pm s.e.m.), in contrast to when $4.0 \pm 4.0 \%$ of the nearby-cell stimulations for soCoChR-expressing neural networks $(P<0.001$, Wilcoxon rank sum test; Fig. 2f,i; mean \pm s.e.m.).

Two-photon holographic control of soCoChR-expressing neurons in brain slice. We next sought to assess the potential for soCoChR to mediate single-cell optogenetic control in intact mouse brain slices. The strong scattering of visible light in tissue will induce a broadening of the excitation spot and therefore spurious activation of distant neurons by both out-of-focus and scattered photons $s^{34,35}$. To avoid this possibility we used $2 \mathrm{P}$ activation, and to optimize temporal resolution we used parallel holographic light illumination. We implemented holographic $2 \mathrm{P}$ activation in two different microscopes (Fig. 3a,b and Supplementary Fig. 6). In setup 1, we combined a custom-made $2 \mathrm{P}$ scanning system with a $2 \mathrm{P}$ CGH setup, using a low-repetition-rate amplified fiber laser $(\lambda=1,030 \mathrm{~nm}$; exit average power $=10 \mathrm{~W}$; repetition rate $=500 \mathrm{kHz}$; pulse duration $=250 \mathrm{fs}$ ) as the excitation source. In setup 2, we combined a $1 \mathrm{P}$ epifluorescence microscope with a $2 \mathrm{P}$ CGH system using as the excitation source a conventional mode-locked Ti:sapphire femtosecond laser $(\lambda=920 \mathrm{~nm}$; exit average power $=1.6 \mathrm{~W}$; repetition rate $=80 \mathrm{MHz}$; pulse duration $=100 \mathrm{fs}$ ). Setup 1 was designed to achieve simultaneous activation of multiple cells, since the high output power and low repetition rate of the laser source enabled parallel illumination with high-energy pulses while keeping average power low. Setup 2, in contrast, had lower output power and used conventional and commonly available laser sources. The tunable laser source used in setup 2 enabled us to tune the excitation wavelength to the peak of the $2 \mathrm{P}$ spectrum (Supplementary Fig. 7), while the laser source used in setup 1 has a fixed excitation wavelength of $1,030 \mathrm{~nm}$, which elicits a current of magnitude $\sim 50 \%$ of that at the excitation peak (Supplementary Fig. 7).

We quantified the spatial confinement of soCoChR vs. CoChR by measuring the photostimulated current integral while steering a $10-\mu \mathrm{m}$-diameter holographic spot away from the soma of a patched neuron in $\sim 10-\mu \mathrm{m}$ steps along a neurite, using a mouse cortical brain slice in the presence of synaptic receptor blockers (NBQX, gabazine, strychnine, APV) (Fig. 3c,d). 2P photostimulation power density was set, for each cell, at the minimum value necessary to reliably (in each of three consecutive trials) trigger one AP using a $30-\mathrm{ms}$ photostimulation pulse illuminating the whole soma (threshold power for CoChR-GFP: $28 \pm 10 \mu \mathrm{W} / \mu \mathrm{m}^{2}$ and $92 \pm 93 \mu \mathrm{W} / \mu \mathrm{m}^{2}$ using setups 1 and 2 , respectively, $n=7$ cells from 5 mice in setup 1 and $n=10$ cells from 8 mice in setup 2; threshold power for soCoChR-GFP: $83 \pm 39 \mu \mathrm{W} / \mu \mathrm{m}^{2}$ and $261 \pm 190 \mu \mathrm{W} / \mu \mathrm{m}^{2}$ using setups 1 and 2, respectively, $n=4$ cells from 4 mice in setup 1 and $n=9$ cells from 6 mice in setup 2). The difference in power required for the two opsins may be due to a difference in expression efficiency for the two opsins in vivo. We cannot exclude the possibility that with the axial resolution used in the experiment $(20-40 \mu \mathrm{m}$; Supplementary Fig. 8), neurites surrounding a given cell body contribute to the observed current, this effect being more pronounced for the non-soma-targeted opsin. For each illumination position along each neurite, we normalized the measured current integral to the corresponding value measured at the soma (Fig. 3e). The normalized current integral decayed more sharply along neurites expressing soCoChR-GFP than along neurites expressing CoChRGFP $(P<0.01$ at sites $30 \mu \mathrm{m}$ from soma and beyond; $n=16$ neurites from 8 CoChR-GFP cells from 7 mice; $n=27$ neurites from 16 soCoChR-GFP cells from 13 mice). We note that the sharper current decay was observed even though for soCoChR-GFP we used higher photostimulation powers than for CoChR-GFP. Absolute values of currents corresponding to Fig. 3e are reported and analyzed in Supplementary Fig. 10 and Supplementary Table 4; the decay of the fluorescence of GFP (fused to the opsin) along the neurites is shown in Supplementary Fig. 9. Thus, photo-evoked currents fell off more rapidly along soCoChR-bearing neurites than those bearing CoChR, a crucial condition to support neuronal stimulation with single-cell resolution.

Millisecond-timescale activation of neurons in brain slices. We next searched for illumination conditions that enabled the triggering of APs with $<1$-ms temporal jitter in cells expressing soCoChR-GFP vs. CoChR-GFP. We measured the rise time $\left(\tau_{\text {on }}\right)$ and decay time $\left(\tau_{\text {off }}\right)$ of photocurrents generated by a holographic spot covering the cell body of an opsin-expressing neuron while we varied illumination power. For both CoChR-GFP- and soCoChRGFP-expressing neurons, $\tau_{\text {on }}$ decreased with increasing illumination power (Fig. 4a), reaching an asymptotic value (see Methods) of $5.7 \pm 2.6 \mathrm{~ms}$ in CoChR-GFP-expressing cells $(n=4$ cells from 4 mice) and $4.1 \pm 2.5 \mathrm{~ms}$ in soCoChR-GFP-expressing cells ( $n=4$ cells from 4 mice). $\tau_{\text {off }}$ values were independent of the illumination power and equal to $37 \pm 13 \mathrm{~ms}$ in CoChR-GFP-expressing cells $(n=4$ cells out of 4 mice) and $33.3 \pm 5.6 \mathrm{~ms}$ in soCoChR-GFP-expressing cells ( $n=4$ cells out of 4 mice). Notably, these numbers were similar, in contrast to what was seen for $1 \mathrm{P}$ widefield illumination in cultured neurons (Fig. 1q), suggesting that restricting light illumination to the soma effectively equalized the decay times of photo-evoked currents for targeted vs. non-targeted opsins.

As a next step in understanding the temporal properties of $2 \mathrm{P}$ $\mathrm{CGH}$ excitation of soCoChR-bearing neurons, we assessed how AP 
Opsin-bearing soma

(i) Cell targeted by light

I Opsin-bearing neurite

Non-opsin-bearing neurite

I Recording electrode
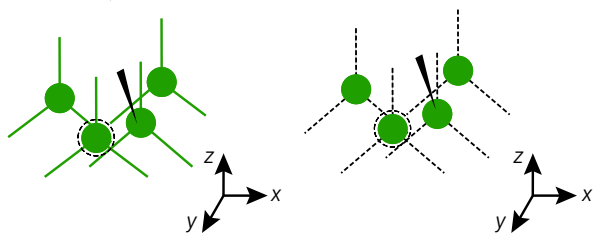

c
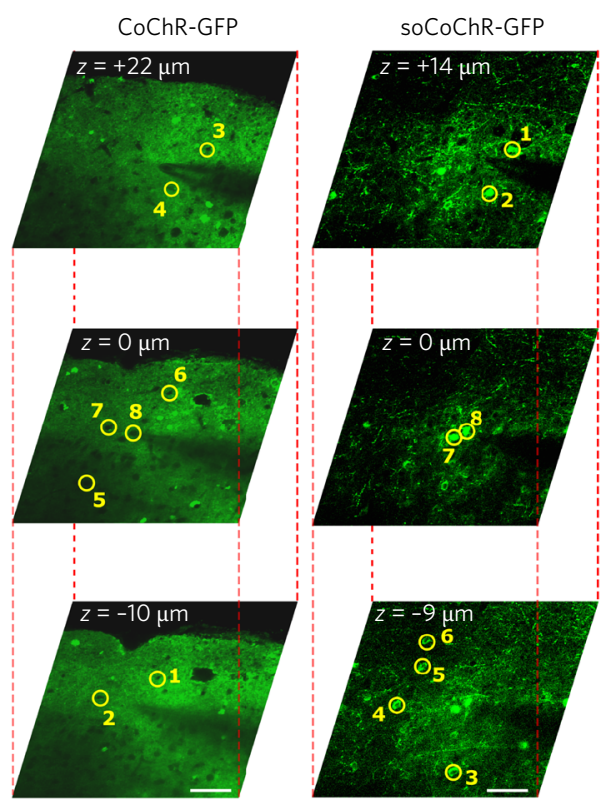

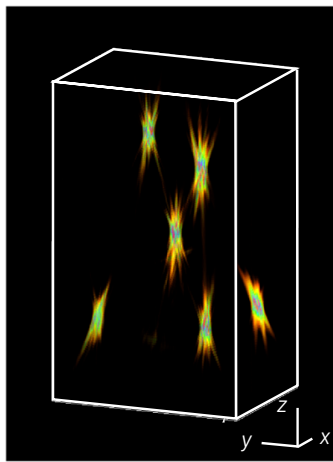
CoChR-GFP

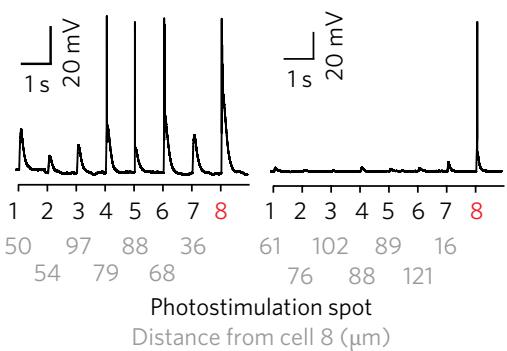

f

Multispot excitation, 7 spots

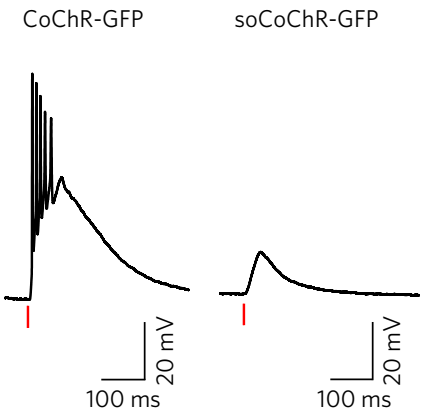

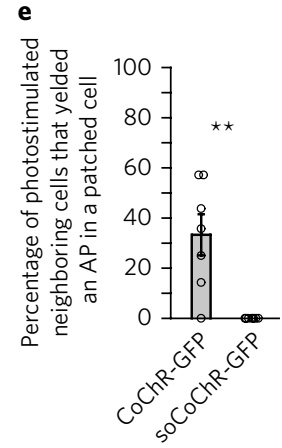

g

Single AP in the patched cell Multiple APs in the patched cell

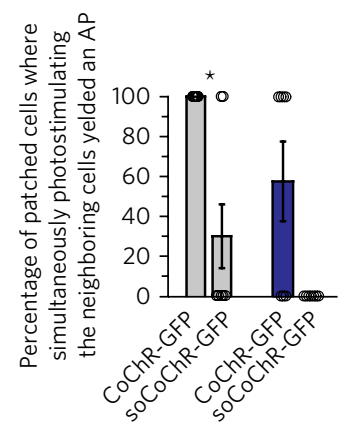

Fig. 5 | Soma-targeted CoChR enables single-cell control with 3D photoactivation in brain slices. a, Schematic of 3D holographic activation. One cell expressing CoChR-GFP or soCoChR-GFP was patched and then neighboring cells in different z-planes were illuminated with 10-14 $\mu$ m diameter holographic spots. b, Reconstruction of multi-spot 3D holographic pattern obtained by measuring induced fluorescence from a thin layer of rhodamine $6 \mathrm{G}$ (spin-coated on a glass coverslip), imaged through a second microscope objective; spot diameter $10 \mu \mathrm{m}$. Scale bars: $35 \mu \mathrm{m}$ along all three axes. c, $2 \mathrm{P}$ images (imaging $\lambda=920 \mathrm{~nm}$ ) from a 3D $z$-stack used to draw 10-14 $\mu \mathrm{m}$ holographic spots $(\lambda=1,030 \mathrm{~nm}$, setup 1$)$ on neighboring cells expressing CoChR-GFP (left, yellow circles numbered 1-7) or soCoChR-GFP (right, yellow circles numbered 1-7) and on the patched cell (yellow circle, numbered 8) inside a volume of approximately $200 \times 200 \times 70 \mu \mathrm{m}^{3}$ (scale bars: $50 \mu \mathrm{m}$ ). d, Whole-cell recording of a CoChR-GFP-expressing cell (left) and a soCoChR-GFP-expressing cell (right) while sequentially positioning the holographic spot on neighboring cells one at a time (represented in $\mathbf{c} ; \lambda=1,030 \mathrm{~nm}$, setup 1 , photostimulation power $100 \mu \mathrm{W} / \mu \mathrm{m}^{2}$ for CoChR-GFP and for soCoChR, $30 \mathrm{~ms}$ duration). The distance of cells 1-7 from the patched cell 8 is given below each cell number in gray. e, Bar plot showing the percentage of neighboring cells that, when stimulated, yielded an AP in a given patched cell (and averaged across all patched cells; $n=7$ cells from 6 mice for CoChR-GFP; $n=7$ cells from 7 mice for soCoChR-GFP; values are mean \pm s.e.m.). Dots denote values for single cells. $\lambda=1,030$ nm, setup 1, average photostimulation power: CoChR-GFP $142 \pm 24 \mu \mathrm{W} / \mu \mathrm{m}^{2}$, soCoChR-GFP $173 \pm 26 \mu \mathrm{W} / \mu \mathrm{m}^{2} ; 30 \mathrm{~ms}$ duration. ${ }^{\star \star} P<0.01$, Wilcoxon rank sum test $(P=0.004)$. f, Wholecell recording of a CoChR-GFP-expressing cell (left) and a soCoChR-GFP-expressing cell (right; both cells presented in d) during simultaneous photostimulation of the neighboring cells represented in $\mathbf{c}$, without a stimulation spot on the soma of the patched cell. Photostimulation power density for each spot was equal to the one used in $\mathbf{d}\left(\lambda=1,030 \mathrm{~nm}\right.$, setup 1, photostimulation power $100 \mu \mathrm{W} / \mu \mathrm{m}^{2}$ for CoChR-GFP and for soCoChRGFP; 30 ms duration, red dash under traces). $\mathbf{g}$, Bar plot showing the percentage of simultaneous photostimulations of neighboring cells that yielded APs in a given patched cell (averaged across all patched cells). Gray bars indicate the generation of 1 AP; blue bars indicate the generation of more than one AP ( $n=7$ cells expressing CoChR-GFP from 6 mice; $n=7$ cells expressing soCoChR-GFP from 7 mice). Values are mean \pm s.e.m. Dots denote values for single cells. $\lambda=1,030 \mathrm{~nm}$, setup 1, average photostimulation power: $142 \pm 24 \mu \mathrm{W} / \mu \mathrm{m}^{2}$ and $173 \pm 26 \mu \mathrm{W} / \mu \mathrm{m}^{2}$ for CoChRGFP-expressing cells and for soCoChR-GFP-expressing cells, respectively; 30 ms duration. For generation of one AP: ${ }^{\star} P<0.05 ; \chi^{2}$ test $\left(\chi^{2}=3.97\right.$, $P=0.046$, d.f. $=1$ ). For generation of more than one AP: $P=0.08, \chi^{2}=3.15$, d.f. $=1$. Average distances between patched cells and neighboring cells are reported in Supplementary Fig. 12 and Supplementary Table 4. 


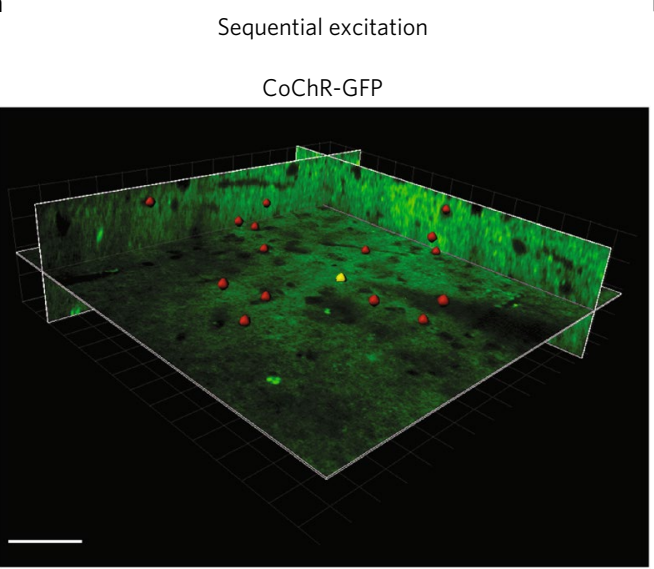

soCoChR-GFP

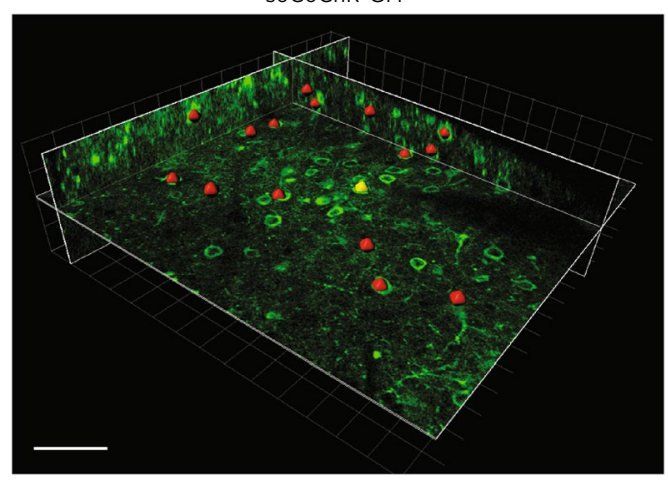

b

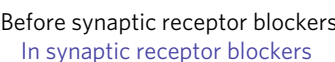
CoChR-GFP

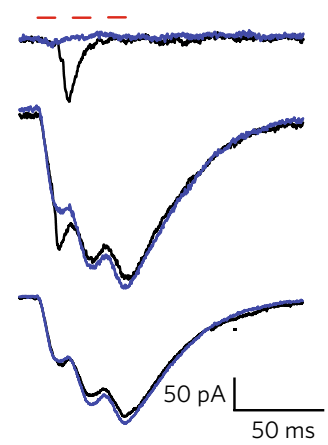

soCoChR-GFP

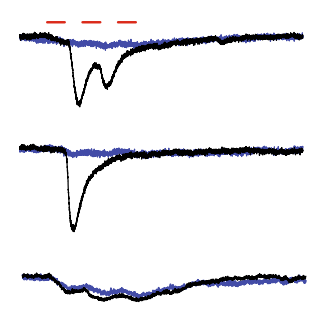

20 pA $50 \mathrm{~ms}$

c Peak of PSCs Peak of artifactual currents
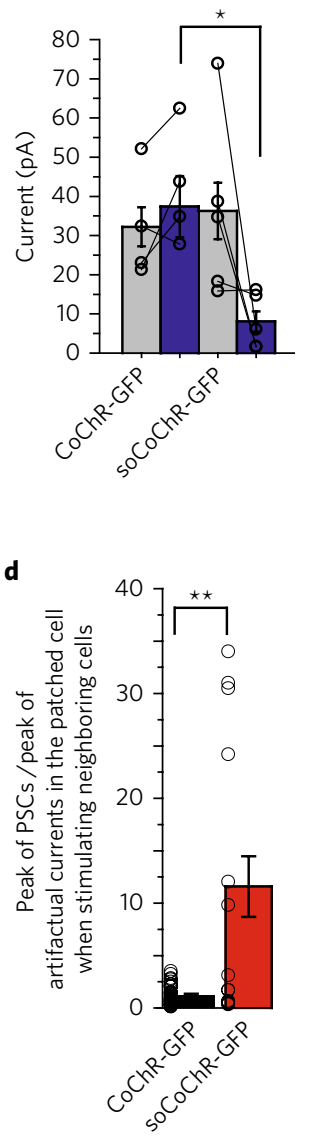

Fig. 6 | 2P holographic stimulation of soCoChR enables mapping of functional connectivity in brain slices. a, Schematic of the connectivity experiment: a $2 \mathrm{P}$ image ( $\lambda=920 \mathrm{~nm}$, setup 1) of the volume around a patched opsin-positive cell (yellow spot) expressing CoChR-GFP (top) or soCoChR-GFP (bottom) is used to sequentially position a 10-14 $\mu \mathrm{m}$ holographic spot (red spots) on nearby opsin-expressing cells and to calculate the corresponding phase masks. Scale bar: $40 \mu \mathrm{m}$. b, Representative currents recorded in whole-cell configuration from a CoChR-GFP-expressing (top) or soCoChR-GFP-expressing (bottom) cell while sequentially positioning the holographic spot on neighboring cells. Red bars represent the photostimulation periods for each cell (three light pulses at $50 \mathrm{~Hz}$ of $10 \mathrm{~ms}$ duration). Photostimulation power: $120 \mu \mathrm{W} / \mu \mathrm{m}^{2}$ for CoChR-GFP; $150 \mu \mathrm{W} / \mu \mathrm{m}^{2}$ for soCoChR-GFP; $\lambda=1,030 \mathrm{~nm}$, setup 1 . Black traces: currents recorded before the perfusion of receptor blockers (average of three trials on each spot position). Blue traces: artifactual currents recorded after the perfusion of receptor blockers (average of three trials on each spot position). c, Bar plots showing the peak amplitudes of postsynaptic currents sensitive to receptor blockers (PSCs; gray bars) and the peak amplitudes of artifactual currents recorded after the perfusion of receptor blockers $\left(I_{\text {ART }}\right.$ blue bars) ( $n=4$ CoChR-GFP cells from 4 mice; $n=5$ soCoChR-GFP cells from 5 mice). Currents were recorded in whole-cell configuration from cells expressing CoChR-GFP or soCoChR-GFP while sequentially positioning the holographic spot on neighboring cells one at a time $(\lambda=920 \mathrm{or} 1,030 \mathrm{~nm}$, setup 1 or 2; photostimulation power (relative to setup 1): $130 \pm 30 \mathrm{~mW} / \mu \mathrm{m}^{2}$ for CoChR-GFP and $180 \pm 20 \mathrm{~mW} / \mu \mathrm{m}^{2}$ for soCoChR-GFP; three light pulses at $50 \mathrm{~Hz}$ of $10 \mathrm{~ms}$ duration). For mean peak current comparison, ${ }^{\star} P=0.015$; Wilcoxon rank sum test. Bars report mean \pm s.e.m. $\mathbf{d}$, Bar plots showing the ratio PSC $/ I_{\text {ART }}(n=54$ out of 78 photostimulated neighboring cells triggering PSCs in the patched cell from 4 CoChR-GFP cells from 4 mice; $n=15$ out of 109 photostimulated neighboring cells triggering PSCs in the patched cell from 5 soCoChR-GFP cells from 5 mice). Currents were recorded in whole-cell configuration from cells expressing CoChR-GFP or soCoChR-GFP while sequentially positioning the holographic spot on neighboring cells one at a time $\left(\lambda=920\right.$ or $1,030 \mathrm{~nm}$, setup 1 or 2 ; photostimulation power (relative to setup 1): $130 \pm 30 \mathrm{~mW} / \mu \mathrm{m}^{2}$ for CoChR-GFP and $180 \pm 20 \mathrm{~mW} / \mu \mathrm{m}^{2}$ for soCoChRGFP; three light pulses at $50 \mathrm{~Hz}$ of $10 \mathrm{~ms}$ duration). For comparison of ratio PSC $/ I_{\text {ART }}$ : ${ }^{\star \star} P=0.003$; Wilcoxon rank sum test. Bars report mean \pm s.e.m.

latency (defined as the time interval between the onset of photoactivation and the peak of the AP) and AP jitter (defined as the standard deviation of the aforementioned latency) depended on the illumination power, for both wild-type CoChR and soCoChR. Increasing the photostimulation power density to values above $70 \mu \mathrm{W} / \mu \mathrm{m}^{2}$ on setup 1 or $360 \mu \mathrm{W} / \mu^{2} \mathrm{~m}^{2}$ on setup 2 enabled, for both CoChR-GFPand soCoChR-GFP-expressing neurons, a spike latency below $15 \mathrm{~ms}$ (Fig. 4b) and a spike jitter below $1 \mathrm{~ms}$ (Fig. 4c).

Single-cell activation of soCoChR-bearing neurons in brain slices using 3D holography. We assessed whether soCoChR-bearing neurons in combination with $2 \mathrm{P}$ holographic stimulation could enable millisecond-precision single-cell optogenetics in brain slices. We performed crosstalk experiments as before, patching an opsinexpressing neuron and attempting to activate both the patched neuron and nearby neurons (Fig. 5a; experiments done using setup 1). We patched an opsin-expressing neuron, with synaptic transmission blocked, and acquired a $2 \mathrm{P}$ image stack to reconstruct the $3 \mathrm{D}$ volume $\left(\sim 200 \times 200 \times 80 \mu \mathrm{m}^{3}\right)$ surrounding the patched cell. $3 \mathrm{D}$ holographic illumination allowed us to sequentially or simultaneously target multiple locations in such a volume (Fig. 5b). We randomly selected five to eight neighboring neurons in this volume (Fig. 5c). We then sequentially illuminated these cells with a $10-14 \mu \mathrm{m}$ holographic spot while recording from the patched cell. 
We used excitation powers above $70 \mu \mathrm{W} / \mu \mathrm{m}^{2}$ that, accordingly to Fig. 4 , ensure $<15$-ms latency and $<1$-ms jitter. In each sequence, for both CoChR-GFP or soCoChR-GFP, the patched cell responded with at least one AP when the holographic spot was placed on its cell body. For CoChR-GFP-expressing cells, in $33 \pm 8 \%$ of the cells near a patched cell ( $n=7$ patched cells from 6 mice; Fig. 5 d,e), illumination evoked an AP in the patched cell, whereas for soCoChRGFP-expressing cells, illumination of neighboring cells one at a time never evoked an AP in the patched cell $(P<0.01 ; n=7$ patched cells from 7 mice; Fig. 5d,e). Thus, soCoChR used in combination with 2P CGH illumination could ensure zero-spike crosstalk, single-cell stimulation of neurons in intact brain circuitry, with $<1$-ms jitter of the resultant spikes.

Although individually illuminating neighboring soCoChR-GFPexpressing cells did not evoke APs in the patched cell, the illumination still induced an average crosstalk depolarization of $2.6 \pm 1 \mathrm{mV}$ in the patched cell (Fig. 5 d; $n=7$ cells from 7 mice). Accordingly, we assessed whether simultaneous stimulation of multiple neighboring cells could push a patched neuron to fire one or more APs, by exciting between five and eight randomly selected neighboring cells. We generated multiple spots, each with power density equal to the one used for the corresponding experiment with sequential cell stimulation $\left(142 \pm 24 \mu \mathrm{W} / \mu \mathrm{m}^{2}\right.$ and $173 \pm 26 \mu \mathrm{W} / \mu \mathrm{m}^{2}$ for CoChR-GFP- and soCoChR-GFP-expressing cells, respectively; see also Methods and Supplementary Fig. 11). For CoChR-GFP, in 57\% of the cells we observed multiple APs ( $n=7$ patched cells from 6 mice; Fig. 5f,g). In contrast, for soCoChR-GFP we never observed multiple APs ( $n=7$ patched cells from 7 mice; Fig. 5f,g). However, single APs were observed in $100 \%$ and $33 \%$ of patched cells for CoChR-GFP and soCoChR-GFP, respectively ( $n=7$ cells from 6 mice and 10 cells from 9 mice, respectively) in the simultaneous excitation condition.

These experiments were done at a power just below saturation (Supplementary Fig. 8d). This enabled us to assure a high enough channel recruitment without too much broadening of the axial resolution (Supplementary Fig. 8d) and consequently helped minimize artifactual out-of-focus neurite activations.

Finally, we performed local functional connectivity experiments in layer II/III of mouse primary visual cortex in brain slices. To this end, we patched a neuron expressing CoChR-GFP or soCoChRGFP and then selected 15-25 neighboring opsin-positive cells in a volume of about $200 \times 200 \times 70 \mu \mathrm{m}^{3}$ centered on the patched cell (Fig. 6a,b and Supplementary Fig. 13). We then sequentially stimulated the neighboring cells (three 10 -ms laser pulses at $50 \mathrm{~Hz}$ ) while recording the currents in the patched cell (Fig. 6a,b) and repeated the entire sequence three times. To trigger APs with short $(<10 \mathrm{~ms})$ latency and millisecond jitter in the presynaptic cells, we applied laser powers in the range of $130 \pm 30 \mu \mathrm{W} / \mu \mathrm{m}^{2}$ for CoChR-GFP and $180 \pm 20 \mu \mathrm{W} / \mu \mathrm{m}^{2}$ for soCoChR-GFP (Fig. $4 \mathrm{~b}, \mathrm{c}$ ). In both preparations, we repeated the same experiment in presence of synaptic receptor blockers (NBQX, gabazine, strychnine, APV) so that we could isolate the synaptic vs. artifactual components.

When performing the experiments in soCoChR-GFP-expressing cells, we found that $13 \pm 7 \%$ of photostimulated neighboring cells evoked currents, here designated $I_{\text {TOT }}$ in the patched cell. The application of synaptic receptor blockers left a residual current $(8 \pm 6 \mathrm{pA}$; Fig. $6 \mathrm{c}$ and Supplementary Table 5) that corresponded to the artifactual component (designated $I_{\mathrm{ART}}$ ), which came from the direct stimulation of dendrites or axons of the patched cell crossing the photostimulation volume. The component sensitive to receptor blockers $\left(I_{\mathrm{TOT}}-I_{\mathrm{ART}}\right)$ was thus an estimate of the true postsynaptic current (PSC) (36 \pm 16 pA; Fig. 6c).

In the case of CoChR-GFP-expressing cells, $71 \pm 14 \%$ of photostimulated neighboring cells evoked currents, $I_{\mathrm{TOT}}$, in the patched cell with an artifactual component, $I_{\mathrm{ART}}$, of $37 \pm 15 \mathrm{pA}$, which was of about the same order as the PSC $(32 \pm 10 \mathrm{pA})$. These results revealed for CoChR the presence of a strong artifactual contribution. Overall, the ratio between the real PSCs and the artifactual peak currents was significantly higher in soCoChR-GFP-expressing cells compared to the case of CoChR-GFP-expressing cells (11 \pm 10 in soCoChR-GFP; $1.4 \pm 1.2$ in CoChR-GFP; Fig. 6d and Supplementary Table 5).

\section{Discussion}

We here demonstrate that optical activation of single cells in dense mammalian neural circuitry, with $<1$-ms temporal jitter, is possible without causing stray spiking in neighboring neurons. We achieved this combined temporally and spatially precise optogenetics through molecular engineering-creating a soma-targeted version of the powerful opsin $\mathrm{CoChR}^{19}$, or soCoChR for short, as well as optimal 2P holographic control of individual neurons. We screened potential trafficking sequences from nine different somalocalized molecules, first testing entire molecules as well as fragments with GFP and then CoChR. The first 150 amino acids on the $\mathrm{N}$ terminus of the kainate receptor subunit 2 enabled efficient targeting of CoChR to the soma, restricting CoChR expression to the first $20-50 \mu \mathrm{m}$ of dendrites and axons, without alteration of cellular function. We showed that we could obtain zero-spike crosstalk $2 \mathrm{P}$ excitation of individual cells-that is, without driving APs in neighbors-but activating many neighbors at once could cause a nearby neuron to be excited to the point of spiking. This remaining multicellular activation crosstalk thus provides an avenue for future investigation.

We performed local functional connectivity experiments in cortical slices and showed that soma-targeted opsins enabled identification and measurement of postsynaptic currents in downstream cells. It is important to note that although the use of soma-targeted CoChR enabled a significant reduction in the artifactual component arising from the direct stimulation of postsynaptic cell processes, this contribution was not completely eliminated. Further improved soma-targeting strategies combined with improved axial confinement of the excitation volume-for example, by combining $\mathrm{CGH}^{12}$ with temporal focusing (Supplementary Fig. 8f,g) - should enable further reductions in this artifactual component.

Optogenetic analysis of synaptic connectivity has been demonstrated before in intact mammalian circuits ${ }^{36,37}$. To avoid artifactual components in the PSCs, some previous studies have used expression of opsins in the presynaptic cell only, thereby ensuring that the postsynaptic cells do not contain an opsin ${ }^{38}$. Alternative strategies have used sparse labeling of the ChR2-expressing neurons ${ }^{39}$ or selective opsin expression in a specific subset of neurons ${ }^{40}$. Pioneering experiments have used ChR2 targeted to the soma through $\mathrm{K}_{\mathrm{v}} 2.1^{30,36}$ together with $1 \mathrm{P}^{36}$ and $2 \mathrm{P}^{33}$ activation. In the latter case, the authors were able to show the use of somatic opsins to map neuronal connectivity. However, these first experiments required long photostimulation pulses $(150 \mathrm{~ms})$ and used relatively high excitation power $(\sim 180 \mathrm{~mW} / \mathrm{cell})^{33}$, which corresponded to a jitter of $17 \mathrm{~ms}$. Thus, earlier efforts had limits on both the maximum number of targets (two to five) that could be simultaneously reached and the precision of the temporal control of spike generation.

Here we demonstrate that using somatic CoChR enables control of neuronal firing using short illumination pulses $(10-30 \mathrm{~ms})$ with temporal jitter short enough $(<1 \mathrm{~ms})$ to control precise neural codes. For soCoChR-GFP-expressing neurons we demonstrate that APs can be generated reliably by using either a conventional modelocked femtosecond Ti:sapphire laser or an amplified fiber laser. The first approach is easier to implement, since such laser sources are common in $2 \mathrm{P}$ microscopy. However, we found that reaching the AP threshold with soCoChR at a depth of about $50 \mu \mathrm{m}$ required an excitation power of about $30 \mathrm{~mW} /$ cell. This value, considering an available exit power after the objective of $\sim 200 \mathrm{~mW}$ (at $920 \mathrm{~nm}$ ), will limit the maximum number of simultaneously achievable targets to six or seven cells. Amplified fiber lasers enable higher 2P absorption compared to typical mode-locked Ti:sapphire laser oscillators due to 
lower pulse repetition rates of the femtosecond laser (the $2 \mathrm{P}$ excited signal $S \propto P_{\text {avg }}^{2}\left(f t_{\mathrm{p}}\right)^{-1}$, with $f$ the repetition rate, $t_{\mathrm{p}}$ the pulse width and $P_{\text {avg }}$ the average beam power $\left.{ }^{41}\right)$. This feature enabled reducing to $\sim 80 \mu \mathrm{W} / \mu \mathrm{m}^{2}$ (corresponding to about $9 \mathrm{~mW} /$ cell) the AP spiking threshold and therefore, considering the several-watt exit power of amplified fiber lasers (corresponding in our setup to $\sim 2 \mathrm{~W}$ after the objective), would make it possible to simultaneously photostimulate up to 200 cells. Performances similar to the one achieved with targeted CoChR and $2 \mathrm{P}$ holographic illumination might be reached by other opsins when fused to the KA2(1-150) motif; for example, Jaws could be used for neuronal inhibition ${ }^{42}$.

Single-cell optogenetics may prove powerful for mapping the connectivity of neurons within functional networks, a topic of great interest in the understanding of how individual cells work together in networks to implement neural computation. Past attempts to map connectivity, either by multi-neuron simultaneous whole-cell patch clamp ${ }^{43}$, by glutamate uncaging onto populations of cells ${ }^{44}$, by examining spontaneous activity in neural networks ${ }^{45}$ or by laserscanning photoactivation of populations of neurons equipped with optogenetic actuators ${ }^{46}$, have revealed many tantalizing and nonrandom features of mammalian neural circuits, with consequences for understanding how individual neurons and networks compute, generate behavior and contribute to brain pathology. With zero-spike crosstalk single-cell optogenetics, it will be possible to patch one neuron and photostimulate many neighboring cells, measuring synaptic strength as well as synaptic release kinetics, and perhaps also to image neural activity network-wide in response to each neuron within the network being excited in turn. Thus, the technologies we report here will be useful for bridging the structural and functional domains of the field of connectomics, important for ultimately realizing its impact on the understanding of behavior and disease.

\section{Methods}

Methods, including statements of data availability and any associated accession codes and references, are available at https://doi. org/10.1038/s41593-017-0018-8.

Received: 3 June 2016; Accepted: 26 September 2017; Published online: 13 November 2017

\section{References}

1. Boyden, E. S. A history of optogenetics: the development of tools for controlling brain circuits with light. F1000 Biol. Repc. 3, 11 (2011).

2. Dombeck, D. A., Harvey, C. D., Tian, L., Looger, L. L. \& Tank, D. W. Functional imaging of hippocampal place cells at cellular resolution during virtual navigation. Nat. Neurosci. 13, 1433-1440 (2010).

3. Li, C.-Y. T., Poo, M.-M. \& Dan, Y. Burst spiking of a single cortical neuron modifies global brain state. Science 324, 643-646 (2009).

4. Houweling, A. R. \& Brecht, M. Behavioural report of single neuron stimulation in somatosensory cortex. Nature 451, 65-68 (2008).

5. Rickgauer, J. P. \& Tank, D. W. Two-photon excitation of channelrhodopsin-2 at saturation. Proc. Natl. Acad. Sci. USA 106, 15025-15030 (2009).

6. Ronzitti, E. et al. Recent advances in patterned photostimulation for optogenetics, J. Opt. 19, 113001 (2017).

7. Papagiakoumou, E. et al. Scanless two-photon excitation of channelrhodopsin-2. Nat. Methods 7, 848-854 (2010).

8. Papagiakoumou, E., de Sars, V., Oron, D. \& Emiliani, V. Patterned twophoton illumination by spatiotemporal shaping of ultrashort pulses. Opt. Express 16, 22039-22047 (2008).

9. Bègue, A. et al. Two-photon excitation in scattering media by spatiotemporally shaped beams and their application in optogenetic stimulation. Biomed. Opt. Express 4, 2869-2879 (2013).

10. Chaigneau, E. et al. Two-photon holographic stimulation of ReaChR. Front. Cell. Neurosci. 10, 234 (2016).

11. Ronzitti, E. et al. Sub-millisecond optogenetic control of neuronal firing with two-photon holographic photoactivation of Chronos. J. Neurosci. https://doi. org/10.1523/JNEUROSCI.1246-17.2017 (2017).

12. Hernandez, O. et al. Three-dimensional spatiotemporal focusing of holographic patterns. Nat. Commun. 7, 11928 (2016).

13. Papagiakoumou, E. et al. Functional patterned multiphoton excitation deep inside scattering tissue. Nat. Photonics 7, 274-278 (2013).
14. Packer, A. M. et al. Two-photon optogenetics of dendritic spines and neural circuits. Nat. Methods 9, 1202-1205 (2012).

15. Anselmi, F., Ventalon, C., Bègue, A., Ogden, D. \& Emiliani, V. Threedimensional imaging and photostimulation by remote-focusing and holographic light patterning. Proc. Natl. Acad. Sci. USA 108, 19504-19509 (2011).

16. Dal Maschio, M., Donovan, J. C., Helmbrecht, T. O. \& Baier, H. Linking neurons to network function and behavior by two-photon holographic optogenetics and volumetric imaging. Neuron 94, 774-789.e5 (2017).

17. Nicholson, C. \& Syková, E. Extracellular space structure revealed by diffusion analysis. Trends Neurosci. 21, 207-215 (1998).

18. Valluru, L. et al. Ligand binding is a critical requirement for plasma membrane expression of heteromeric kainate receptors. J. Biol. Chem. 280, 6085-6093 (2005)

19. Klapoetke, N. C. et al. Independent optical excitation of distinct neural populations. Nat. Methods 11, 338-346 (2014).

20. Jacobs, E. C., Bongarzone, E. R., Campagnoni, C. W., Kampf, K. \& Campagnoni, A. T. Soma-restricted products of the myelin proteolipid gene are expressed primarily in neurons in the developing mouse nervous system. Dev. Neurosci. 25, 96-104 (2003).

21. Lim, S. T., Antonucci, D. E., Scannevin, R. H. \& Trimmer, J. S. A novel targeting signal for proximal clustering of the Kv2.1 $\mathrm{K}^{+}$channel in hippocampal neurons. Neuron 25, 385-397 (2000).

22. Garrido, J. J. et al. A targeting motif involved in sodium channel clustering at the axonal initial segment. Science 300, 2091-2094 (2003).

23. Schäfer, M. K. E. et al. L1 syndrome mutations impair neuronal L1 function at different levels by divergent mechanisms. Neurobiol. Dis. 40, 222-237 (2010).

24. Bianco, A., Dienstbier, M., Salter, H. K., Gatto, G. \& Bullock, S. L. Bicaudal-D regulates fragile $\mathrm{X}$ mental retardation protein levels, motility, and function during neuronal morphogenesis. Curr. Biol. 20, 1487-1492 (2010).

25. Ran, B., Bopp, R. \& Suter, B. Null alleles reveal novel requirements for Bic-D during Drosophila oogenesis and zygotic development. Development 120, 1233-1242 (1994).

26. Zhang, X. \& Bennett, V. Restriction of $480 / 270-\mathrm{kD}$ ankyrin $\mathrm{G}$ to axon proximal segments requires multiple ankyrin G-specific domains. J. Cell Biol. 142, 1571-1581 (1998).

27. Wu, C., Ivanova, E., Zhang, Y. \& Pan, Z.-H. rAAV-mediated subcellular targeting of optogenetic tools in retinal ganglion cells in vivo. PLoS One 8 , e66332 (2013).

28. Greenberg, K. P., Pham, A. \& Werblin, F. S. Differential targeting of optical neuromodulators to ganglion cell soma and dendrites allows dynamic control of center-surround antagonism. Neuron 69, 713-720 (2011).

29. Marchler-Bauer, A. et al. CDD: NCBI's conserved domain database. Nucleic Acids Res. 43, D222-D226 (2015).

30. Ren, Z. et al. Multiple trafficking signals regulate kainate receptor KA2 subunit surface expression. J. Neurosci. 23, 6608-6616 (2003).

31. Grubb, M. S. \& Burrone, J. Channelrhodopsin-2 localised to the axon initial segment. PLoS One 5, el3761 (2010).

32. Zhang, Z., Feng, J., Wu, C., Lu, Q. \& Pan, Z.-H. Targeted expression of channelrhodopsin-2 to the axon initial segment alters the temporal firing properties of retinal ganglion cells. PLoS One 10, e0142052 (2015).

33. Baker, C. A., Elyada, Y. M., Parra, A. \& Bolton, M. M. Cellular resolution circuit mapping with temporal-focused excitation of soma-targeted channelrhodopsin. Elife 5, e14193 (2016).

34. Helmchen, F. \& Denk, W. Deep tissue two-photon microscopy. Nat. Methods 2, 932-940 (2005).

35. Szabo, V., Ventalon, C., De Sars, V., Bradley, J. \& Emiliani, V. Spatially selective holographic photoactivation and functional fluorescence imaging in freely behaving mice with a fiberscope. Neuron 84, 1157-1169 (2014).

36. Brill, J., Mattis, J., Deisseroth, K. \& Huguenard, J. R. LSPS/optogenetics to improve synaptic connectivity mapping: unmasking the role of basket cell-mediated feedforward inhibition. eNeuro 3, ENEURO.0142-15.2016 (2016).

37. Kohara, K. et al. Cell type-specific genetic and optogenetic tools reveal hippocampal CA2 circuits. Nat. Neurosci. 17, 269-279 (2014).

38. Little, J. P. \& Carter, A. G. Subcellular synaptic connectivity of layer 2 pyramidal neurons in the medial prefrontal cortex. J. Neurosci. 32, 12808-12819 (2012).

39. Pala, A. \& Petersen, C. C. In vivo measurement of cell-type-specific synaptic connectivity and synaptic transmission in layer $2 / 3$ mouse barrel cortex. Neuron 85, 68-75 (2015).

40. Liu, X. et al. Optogenetic stimulation of a hippocampal engram activates fear memory recall. Nature 484, 381-385 (2012).

41. Xu, C. \& Webb, W. W. Measurement of two-photon excitation cross sections of molecular fluorophores with data from 690 to $1050 \mathrm{~nm}$. J. Opt. Soc. Am. B 13, 481 (1996)

42. Chuong, A. S. et al. Noninvasive optical inhibition with a red-shifted microbial rhodopsin. Nat. Neurosci. 17, 1123-1129 (2014). 
43. Song, S., Sjöström, P. J., Reigl, M., Nelson, S. \& Chklovskii, D. B. Highly nonrandom features of synaptic connectivity in local cortical circuits. PLoS Biol. 3, e68 (2005).

44. Yoshimura, Y., Dantzker, J. L. M. \& Callaway, E. M. Excitatory cortical neurons form fine-scale functional networks. Nature 433, 868-873 (2005).

45. Ikegaya, Y. et al. Synfire chains and cortical songs: temporal modules of cortical activity. Science 304, 559-564 (2004).

46. Petreanu, L., Huber, D., Sobczyk, A. \& Svoboda, K. Channelrhodopsin-2assisted circuit mapping of long-range callosal projections. Nat. Neurosci. 10, 663-668 (2007).

\section{Acknowledgements}

We thank M. Gajowa for participating in preliminary opsin screening, F. Simony and M. Gajowa for help with viral injections, C. Tourain for technical support in building the holographic system, V. de Sars for software development and J. Cécile for help with $\mathrm{CHO}$ cell culture and transfection. V.E. thanks the Agence Nationale de la Recherche (ANR-10-INBS-04-01, France-BioImaging Infrastructure network; ANR-14-CE13-0016, Holohub), the National Institutes of Health (NIH 1-U01-NS090501-01), the FRC and the Rotary Club through the program Espoir en Tete and the Getty Lab. O.A.S. thanks the Simons Foundation for the Social Brain Fellowship and the ISEF (International Sephardic Educational Foundation) for an ISEF postdoctoral fellowship. This research was also developed with funding from the Defense Advanced Research Projects Agency (DARPA), contract No. N66001-17-C-4015. The views, opinions and/or findings expressed are those of the author and should not be interpreted as representing the official views or policies of the Department of Defense or the US Government. V.E. and E.S.B. thank the Human Frontiers Science Program (Grant RGP0015/2016) for financial support. E.S.B. additionally acknowledges, for funding, John Doerr, the Open
Philanthropy Project, the HHMI-Simons Faculty Scholars Program, NIH R44EB021054, the MIT Media Lab, NIH 1R24MH106075, NIH 2R01DA029639, NIH 1R01NS087950, NIH 1R01MH103910, NIH Director's Pioneer Award 1DP1NS087724 and NIH 1R01GM104948.

\section{Author contributions}

O.A.S. designed, screened and tested soma-targeted opsins. O.A.S., C.L. and K.P. performed and analyzed $1 \mathrm{P}$ experiments in cultured cells. V.Z. and D.T. performed and analyzed $2 \mathrm{P}$ experiments in cultured cells and brain slices. V.Z. performed and optimized virus injection and implemented electrophysiological recording on the $2 \mathrm{P}$ rigs. E.R. and E.P. designed and built up setup 1. D.T. designed and built up setup 2, optimized multicell stimulation and designed calibration procedures. O.A.S., E.S.B., D.T., V.Z. and V.E. interpreted data, designed experiments, and wrote the paper with contributions from all authors. E.S.B. and V.E. conceived and supervised the project.

\section{Competing interests}

O.A.S., E.S.B. and C.L. are inventors on pending patents covering the described work.

\section{Additional information}

Supplementary information is available for this paper at https://doi.org/10.1038/ s41593-017-0018-8.

Reprints and permissions information is available at www.nature.com/reprints. Correspondence and requests for materials should be addressed to E.S.B. or V.E. Publisher's note: Springer Nature remains neutral with regard to jurisdictional claims in published maps and institutional affiliations. 


\section{Methods}

Primary neuron culture, transfection and transduction. All procedures involving animals were in accordance with the National Institutes of Health Guide for the Care and Use of Laboratory Animals and approved by the Massachusetts Institute of Technology Animal Care and Use Committee. Hippocampal neuron cultures were prepared from postnatal day 0 or day 1 Swiss Webster (Taconic or Charles River) mice as previously described ${ }^{19}$.

For neuronal expression of GFP fusions with opsins or GFP fusions with trafficking sequences during the screen for soma targeting sequences, we performed transfection at 4 days in vitro (DIV) with a commercial calcium phosphate kit (Invitrogen). We added an additional washing step with acidic MEM buffer ( $\mathrm{pH}$ 6.8-6.9) after calcium phosphate precipitate incubation to completely resuspend residual precipitates ${ }^{47}$. We used $1 \mu \mathrm{g}$ of DNA. Neurons were imaged 14-18 DIV (10-14 d after transfection).

For neuronal expression of mCherry we transduced the already transfected neurons at 10-14 DIV with AAV8-Syn-mCherry-WPRE virus by adding $1 \mu \mathrm{l}$ of the virus (titer $1.4 \times 10^{13}$ infectious units per $\mathrm{mL}$ )

For neuronal expression of either CoChR-GFP or soCoChR-GFP in culture (as seen in Fig. 2), hippocampal cultures were transduced at 3-4 DIV with either AAV8-Syn-CoChR-GFP-WPRE or AAV8-Syn-soCoChR-GFP-WPRE viruses (at a titer of $4.7 \times 10^{12}$ and $4.0 \times 10^{12}$, respectively) and imaged $14 \mathrm{~d}$ later.

AAV particles were produced by the University of North Carolina Chapel Hill Vector Core.

Whole-cell electrophysiology in vitro. Current and voltage clamp recordings of cultured neurons. Whole cell patch clamp recordings in culture were made using Axopatch 200B or Multiclamp 700B amplifiers, a Digidata 1440 digitizer and a PC running pClamp (Molecular Devices). For in vitro current-clamp recordings, neurons were patched at 14-18 DIV (10-14 d after transfection) to allow neurons to mature to the point of being capable of spiking. Neurons were bathed in room temperature Tyrode buffer containing $125 \mathrm{mM} \mathrm{NaCl}, 2 \mathrm{mM} \mathrm{KCl}, 3 \mathrm{mM} \mathrm{CaCl}$, $1 \mathrm{mM} \mathrm{MgCl}, 10 \mathrm{mM}$ HEPES, $30 \mathrm{mM}$ glucose and the receptor blockers $0.01 \mathrm{mM}$ NBQX and $0.01 \mathrm{mM}$ gabazine. The Tyrode $\mathrm{pH}$ was adjusted to 7.3 with $\mathrm{NaOH}$ and the osmolarity was adjusted to $300 \mathrm{mOsm}$ with sucrose. For in vitro voltage-clamp recordings, neurons were patched at 19-21 DIV (17-20 d after transfection) under similar conditions as for the current-clamp recordings, except the Tyrode also contained $1 \mu \mathrm{M}$ tetrodotoxin (Tocris Bioscience). No all-trans-retinal was added for any cultured neuron recordings.

For recordings, borosilicate glass pipettes (Warner Instruments) with an outer diameter of $1.2 \mathrm{~mm}$ and a wall thickness of $0.255 \mathrm{~mm}$ were pulled to a resistance of $5-10 \mathrm{M} \Omega$ with a P-97 Flaming/Brown micropipette puller (Sutter Instruments) and filled with a solution containing $125 \mathrm{mM}$ potassium gluconate, $8 \mathrm{mM} \mathrm{NaCl}, 0.1 \mathrm{mM}$ $\mathrm{CaCl}_{2}, 0.6 \mathrm{mM} \mathrm{MgCl}_{2}, 1 \mathrm{mM}$ EGTA, $10 \mathrm{mM}$ HEPES, $4 \mathrm{mM} \mathrm{Mg}$-ATP and $0.4 \mathrm{mM}$ $\mathrm{Na}-\mathrm{GTP}$. The pipette solution $\mathrm{pH}$ was adjusted to 7.3 with $\mathrm{KOH}$ and the osmolarity was adjusted to $298 \mathrm{mOsm}$ with sucrose. For voltage clamp experiments, cells were clamped at $-65 \mathrm{mV}$. For current clamp experiments, access resistance was monitored throughout recording. Data were analyzed using Clampfit (Molecular Devices) and custom Matlab scripts (MathWorks, Inc.).

Current clamp recordings of cultured neurons during digital micromirror device (DMD) photostimulation experiments. Whole-cell patch clamp recordings were made using Axopatch 200B or Multiclamp 700B amplifiers, a Digidata 1440 digitizer and a PC running pClamp (Molecular Devices). In each experiment (Fig. 2), we patched (current clamp) cell 1 . Then, starting from cell 1, we photostimulated cell 1 and 9 other cells using the DMD to focus the light. Photostimulations were made $10 \mathrm{~s}$ apart $\left(470 \mathrm{~nm} ; 40.7 \mathrm{~mW} / \mathrm{mm}^{2}\right)$ and the responses for the photostimulation were recorded in pClamp.

Molecular cloning and virus production. All opsin genes were synthesized (Genscript) with mammalian codon optimization and subcloned as previously described $^{19,48}$. For screening in cultured neurons, all genes were subcloned into the FCK lentiviral backbone under a CaMKII promoter (derived from the promoter from the gene Camk2a) and with a C-terminal GFP fusion. For soCoChR-GFP, the first 450 bp were cloned $3^{\prime}$ to $\mathrm{CoChR}$, with no further trafficking sequences added. For CoChR-Na $\mathrm{V}_{\mathrm{V}}$ 1.2(II-III)-GFP, we added the $\mathrm{KGC}^{49}$ followed by ER2 ${ }^{50}$ trafficking sequences from the potassium channel Kir2.1, with the resulting molecule named CoChR-KGC-Na 1 1.2(II-III)-ER2-GFP (see ref. ${ }^{42}$ for earlier details). For virus production, the genes were cloned into the pAAV plasmid, using a synapsin promoter. AAV (serotype 8) was produced by the UNC vector core.

Photostimulation experiments in vitro. Whole field neural stimulation. Neuron voltage clamp photostimulation experiments were done with a LED mounted on a microscope for widefield illumination (Leica 3000B), with a nominal wavelength of $480 \mathrm{~nm}$ (X-Cite XLED1, Excelitas Technologies). We filtered the LED light with the $472 / 30 \mathrm{~nm}$ BrightLine single-band bandpass filter (Semrock). Light was triggered by pClamp (Molecular Devices). Light power was measured as $34.84 \mathrm{~mW} / \mathrm{mm}^{2}$ through a Leica HCX APO L $40 \times$ objective (air, NA 0.6). For each trace recorded, a 10 -ms current injection was given (to make sure a neuron could spike), followed by a $1-\mathrm{ms}$ light pulse $\left(480 \mathrm{~nm} ; 34.84 \mathrm{~mW} / \mathrm{mm}^{2}\right) 5 \mathrm{~s}$ later.
Stimulation of cell bodies with a DMD. Stimulation of neural cell bodies was performed with a Leica 6000 B widefield microscope mounted with a Mosaic DMD system (Andor) and a Zyla 5.5 sCMOS camera (Andor). The experiments were performed with an LED with a nominal wavelength of $470 \mathrm{~nm}$ (Thorlabs, M470L2) and power of $40.7 \mathrm{~mW} / \mathrm{mm}^{2}$. Neurons were imaged and stimulated through a 1 MP-2262-59022XR-360T GFP/mCherry filter set (dual GFP/mCherry, Andor). For the photostimulation experiment, an image of the green fluorescence was first acquired, and cell bodies were then identified by eye on the basis of their doughnut-shaped fluorescence. A cell was chosen at random to be patched (to avoid sample bias, we patched the neuron that was closest to the middle of the field of view), with the only requirement being that it was in a dense area. This cell was referred to as cell 1 . Thereafter, 9 circles with a diameter of $20 \mu \mathrm{m}$ were defined around cell bodies of interest using MetaMorph software (Molecular Devices) with distances ranging between 10 and $200 \mu \mathrm{m}$ from cell 1 . Then, starting from cell 1 , we photostimulated cell 1 and the 9 other cells sequentially. Stimulations were made 10 s apart.

Single-photon characterization of CoChR and soCoChR. Action spectrum data for CoChR and soCoChR were taken and analyzed as previously described ${ }^{19}$. Analysis of spike probability as a function of irradiance for CoChR- and soCoChR-expressing cells, photocurrent as a function of irradiance for CoChRand soCoChR-expressing cells, and light-driven spike fidelity for CoChR- and soCoChR-expressing cells were all determined as previously described ${ }^{19}$.

Imaging in vitro. GFP fusions with trafficking sequences, opsin-GFP with trafficking sequences, and cytosolic mCherry expressed in cultured neurons were imaged with a LED (X-Cite XLED1, Excelitas Technologies) mounted on a microscope for widefield illumination (Leica 3000B) through either a Leica HCX APO L $40 \times$ objective (air, NA 0.6) or a Leica HCX APO L $20 \times$ objective (air, NA =0.5). Imaging was performed with a Hamamatsu Orca Flash 4.0 camera under identical illumination conditions throughout: a 480-nm LED using a GFP$3035 \mathrm{D}$ filter cube (Semrock) for GFP fluorescence $\left(34.84 \mathrm{~mW} / \mathrm{mm}^{2}\right.$ ) and a $540-\mathrm{nm}$ LED with a $543 \mathrm{~nm} \pm 11 \mathrm{~nm}$ excitation filter (Semrock) for mCherry fluorescence. Images were taken with an exposure time of $300 \mathrm{~ms}$.

Cultured neurons expressing CoChR-GFP, KA2-GFP or KA2(1-150)-GFP were imaged using similar parameters: fluorescence was excited with a $480 \mathrm{~nm}$ LED filtered by a $472 / 30 \mathrm{~nm}$ BrightLine single-band bandpass filter (Semrock) and focused on the sample through a Leica HCX APO L $20 \times$ objective (air, NA 0.6), with a power of $25.19 \mathrm{~mW} / \mathrm{mm}^{2}$. Images were acquired with a Hamamatsu Orca Flash 4.0 with an exposure time of $300 \mathrm{~ms}$.

\section{Viral injections and whole-cell electrophysiology in brain slices. All} experimental procedures were conducted in accordance with guidelines from the European Union and institutional guidelines on the care and use of laboratory animals (council directive 86/609 of the European Economic Community) that were approved by the Paris Descartes Ethics Committee for Animal Research (registration number CEEA34.EV.118.12).

Stereotactic injections of the viral vectors AAV8-Syn-CoChR-GFP, AAV8Syn -CoChR-KGC-Na 1 1.2(II-III)-GFP-ER2 and AAV8-Syn-soCoChR-GFP were performed in 4-week-old male Swiss mice (Janvier Labs). For connectivity experiments the promoters Syn (derived from the human SYN1 promoter), CaMKII (derived from the promoter from Camk2a) or CAG were used. Animals were housed from 3 to 5 per cage with a light dark cycle of $12+12 \mathrm{~h}$. Mice were anesthetized with a ketamine $(80 \mathrm{mg} / \mathrm{kg})$-xylazine $(5 \mathrm{mg} / \mathrm{kg})$ solution and a small craniotomy $(0.7 \mathrm{~mm})$ was made on the skull overlying V1 cortex. An injection of $1-1.5 \mu \mathrm{l}$ solution containing the viral vector was made with a cannula at about $80-100 \mathrm{nl} / \mathrm{min}$ at $200-250 \mu \mathrm{m}$ below the dural surface. The skin was sutured and the mouse recovered from anesthesia.

Brain slices of V1 cortex were prepared from mice $7-15$ weeks after viral injection. Mice were deeply anesthetized with isoflurane (5\% in air) and decapitated, and the brain was rapidly removed. Sagittal slices $300 \mu \mathrm{m}$ thick were obtained (VT1200S Leica Biosystems, Germany) in room temperature or ice-cold solution containing the following (in $\mathrm{mM}$ ): $85 \mathrm{NaCl}, 2.5 \mathrm{KCl}, 0.5 \mathrm{CaCl}_{2}, 4 \mathrm{MgCl}_{2}$, 65 sucrose, 25 glucose, 0.5 ascorbic acid. Slices were transferred to a recovery chamber held at $35^{\circ}$ for $45 \mathrm{~min}$, in a bath containing $20 \%$ sucrose solution and $80 \%$ ACSF containing the following (in $\mathrm{mM}$ ): $125 \mathrm{NaCl}, 2.5 \mathrm{KCl}, 26 \mathrm{NaHCO}_{3}$, $1.25 \mathrm{NaH}_{2} \mathrm{PO}_{4}, 1 \mathrm{MgCl}_{2}, 1.5 \mathrm{CaCl}_{2}, 25$ glucose, 0.5 ascorbic acid. All solutions were aerated with $95 \% \mathrm{O}_{2}$ and $5 \% \mathrm{CO}_{2}$ to a final $\mathrm{pH}$ of 7.4 .

Slices were placed in a recording chamber under the microscope objective and were patched while monitoring IR transmitted light images acquired at approximately video rate. Cells were patched at $40-70 \mu \mathrm{m}$ depth and clamped at $-70 \mathrm{mV}$ in voltage-clamp configuration. Membrane potential was kept at $-70 \mathrm{mV}$ with current injections ranging from -5 to $-35 \mathrm{pA}$ in current-clamp configuration. Cell type was established on the basis of morphology and AP firing properties. Electrophysiology data were acquired with a Multiclamp 700B amplifier, a Digidata 1322 A digitizer (Molecular Devices) or a National Instrument device, and a PC running pClamp10 software (Molecular Devices) or Neuromatic software running on the IgorPro interface (Wavemetrics). Voltage and current clamp recordings were filtered at $6-10 \mathrm{kHz}$ and sampled at $20-50 \mathrm{kHz}$. On the curves displayed in 
Fig. 3, a smoothing of between 150 and 250 data points was applied, and in Fig. 5 a smoothing of 10 data points was applied.

The following receptor blockers were added to the artificial cerebrospinal fluid (ACSF) solution in all experiments to block any synaptic effect: strychnine, picrotoxin, gabazine and NBQX (1-5 $\mu \mathrm{M}$ each; from Abcam or Tocris). Borosilicate glass pipettes (outer diameter $1.5 \mathrm{~mm}$ and inner diameter $0.86 \mathrm{~mm}$ ) were pulled with a micropipette puller (Sutter Instruments) and filled with a solution containing the following (in $\mathrm{mM}$ ): 130 potassium gluconate, $7 \mathrm{KCl}, 4 \mathrm{Mg}$-ATP, $0.3 \mathrm{mM}$ Na-GTP, 10 sodium phosphocreatine and $10 \mathrm{mM}$ HEPES ( $\mathrm{pH}$ adjusted to 7.28 with $\mathrm{KOH}$; osmolarity $280 \mathrm{mOsm}$ ). Pipette resistance in the bath was 5-7 M $\Omega$. Data were acquired with a Multiclamp 700B amplifier, a Digidata 1322 A digitizer (Molecular Devices) or a National Instrument device, and a PC running pClamp10 software (Molecular Devices) or Neuromatic software running on the IgorPro interface (Wavemetrics).

Imaging and photostimulation in brain slices. Holographic photostimulation was implemented in two different setups, with two different photostimulation laser sources and imaging systems. Setups 1 and 2 were used to acquire the data presented in Figs. 3, 4 and 6 whereas data presented in Fig. 5 were acquired solely with setup 1.

Setup 1. Setup 1 consists of a homemade system, built around a commercial upright microscope (SliceScope, Scientifica) in which the holographic photostimulation path was combined with three imaging pathways: a two-photon (2P) rasterscanning pathway, a one-photon (1P) widefield epifluorescence pathway and an infrared (IR) transmitted-light imaging pathway (see schematic in Supplementary Fig. 6). 2P imaging was performed with a pulsed Ti:sapphire laser source (Coherent Chameleon Vision II, pulse width $140 \mathrm{fs}$, tuning range $680-1,080 \mathrm{~nm}$ ). The beam was raster scanned across the sample via a pair of $x y$ galvanometric mirrors (3-mm aperture, $6215 \mathrm{H}$ series, Cambridge Technology) imaged at the back aperture of the microscope objective (40× W APO NIR, Nikon) through an afocal telescope (scan lens: $f=100 \mathrm{~mm}$, Thorlabs AC508-300-B; tube lens: $f=300 \mathrm{~mm}$, Thorlabs AC508-100-B). Fluorescence was collected with a fiber-coupled detection scheme ${ }^{51}$ based on a large-diameter collector lens $(f=75 \mathrm{~mm}$, Thorlabs LB1309-A) and a 5-mm-diameter liquid light guide (LLG, Series 300, Lumatec customized with a $f=14.5 \mathrm{~mm}$ doublet lens glued at the fiber entrance, by Till Photonics, and an antireflective coating provided at the fiber exit). The exit of the fiber was projected onto two GaAsP photomultiplier tubes (H10770-40 SEL, Hamamatsu H10770-40 SEL, active area $5 \mathrm{~mm})$ by a set of three matching aspheric lenses $(f=23.5 \mathrm{~mm}$, Melles Griot LAG-32.5-23.5-C). Fluorescence light was filtered by an IR-blocking filter (FF01-750sp, Semrock), spectrally split into two channels by a dichroic mirror (FF555-Di03, Semrock) and further filtered through two emission filters (FF01-510/84 and FF02-617/73, Semrock). The power of the 2P imaging laser was controlled through a liquid crystal variable phase retarder (LRC-200-IR1, Meadowlark Optics) and a polarizer cube (BB-050-IR1, Meadowlark Optics).

$1 \mathrm{P}$ imaging was based on illumination provided by a LED source (M470L2, Thorlabs), whose emission spectra was filtered by a bandwidth excitation filter (FF01-452/45, Semrock). To provide homogenous widefield illumination, the emission was directed though a diffuser (DG10-1500, Thorlabs) and successively through an achromatic lens ( $f=30 \mathrm{~mm}$, LA1805 Thorlabs). 1P-induced fluorescence, after being separated from the excitation light using a dichroic mirror (FF510-Di02, Semrock), was collected through a tube lens $(f=200 \mathrm{~mm})$, filtered by a band-pass filter (FF01-609/181, Semrock) and detected by a CCD camera (Orca$05 \mathrm{G}$, Hamamatsu). Fluorescence induced by $2 \mathrm{P}$ raster scanning or by $1 \mathrm{P}$ widefield illumination was collected by PMTs or a CCD, respectively; in the detection pathway we had a switchable dichroic mirror (FF705-Di01, 70×50 mm custom size, Semrock)

The transmitted IR oblique illumination imaging path was based on an IR LED source (M780L2, Thorlabs), coupled with a DODT-contrast tube (DODT tube, Scientifica) and a condenser. Light transmitted through the sample was collected with an IR CCD (IR-1000, DAGE-MIT).

$2 \mathrm{P}$ photoactivation consisted of arbitrary illumination patterns obtained with computer-generated holography, based on phase modulation of the laser wave front via the use of a spatial light modulator (SLM).

The laser source used consisted of a femtosecond pulsed beam delivered by a fiber laser source (pulse width $250 \mathrm{fs}$, repetition rate $500 \mathrm{kHz}$, pulse energy $20 \mu \mathrm{J}$, $\lambda=1,030 \mathrm{~nm}$; Satsuma, Amplitude Systems). The beam was enlarged by a telescope and reflected off the SLM (LCOS-SLM X10468-07, Hamamatsu Photonics). The beam was then projected on the back focal plane of the objective with a double afocal telescope $(f=500 \mathrm{~mm}$ Thorlabs AC508-500-B, $f=300 \mathrm{~mm}$, Thorlabs AC508$300-\mathrm{B}, f=200 \mathrm{~mm}$, Thorlabs AC508-200-B and $f=300 \mathrm{~mm}$ Thorlabs AC508$300-B)$. The SLM was driven by custom-designed software (Wave Front Designer ${ }^{52}$ ) based on a Gerchberg and Saxton (GS) iterative algorithm ${ }^{53}$ that converts an arbitrary intensity pattern on the sample plane to a specific phase profile to be addressed at the SLM plane.

As originally described for low- $\mathrm{NA}^{54}$ and, more recently, high-NA objectives ${ }^{12}$, adding lens-phase modulations to 2D-phase holograms enables remote axial displacement and 3D positioning of bidimensional light patterns. This allowed us to target neural processes, following their path in $x-y$ - $z$ (Fig. 3), and to address multiple targets, sequentially or simultaneously, on multiple planes (Figs. 5 and 6).
The zeroth order of diffraction was eliminated by introducing a single or a double cylindrical lens ${ }^{55} .2 \mathrm{P}$ imaging scanning and $2 \mathrm{P}$ photoactivation beams were combined through a large dichroic mirror (Chroma T970dcspxr, $50 \mathrm{~mm} \times 70 \mathrm{~mm}$ custom size, Chroma).

Setup 2. An analogous holographic photostimulation path was coupled with widefield epifluorescence imaging on a second system, here denoted as setup 2 (see Supplementary Fig. 6). This system was built around an Olympus BX51WI upright microscope, capable of widefield epifluorescence imaging using illumination with an arc lamp (OptoSource Illuminator, Cairn Research, coupled with a monochromator, Optoscan Monochromator, Cairn Research), and an Orca Flash 4.0 Hamamatsu sCMOS camera for epifluorescence imaging. The native infrared differential interference contrast (DIC) path of the Olympus microscope allowed DIC imaging on the camera. The holographic photoactivation laser source consisted of a conventional pulsed Ti:sapphire laser used at $920 \mathrm{~nm}$ (pulse width: $100 \mathrm{fs}$, repetition rate: $80 \mathrm{MHz}$, Mai-Tai, Deep-See, Spectra Physics).

The holographic path was analogous to the one described for setup 1: a beam expander enlarged the beam in front of the spatial light modulator (LCOS-SLM X10468-02), whose plane was projected at the back focal plane of a $40 \times$, NA 0.8 objective (LUM PLAN FI/IR, Olympus) by an afocal telescope $(f=750 \mathrm{~mm}$, Thorlabs AC508-750-B and $f=500 \mathrm{~mm}$ Thorlabs AC508-500-B). The holographic beam was coupled to the optical axis of the microscope by a dichroic mirror (FF670, SDi01, $25 \times 36 \mathrm{~mm}$, Semrock). Photostimulation light pulses were generated by a Pockels cell (350-80, Conoptics). For the experiments in Fig. 6, setup 2 was upgraded with a commercial $2 \mathrm{P}$ scanning imaging module (VIVO, 2-PHOTON, 3i-Intelligent Imaging Innovations).

Power conversion between setups 1 and 2 . The differences between the illumination conditions (wavelength, pulse width and repetition rate) used in setups 1 and 2 required finding a proper criterion to compare the experiments performed on the two setups. To do so, we empirically estimated a scaling conversion factor $k$ between the power of the two systems, $P_{1}$ on setup 1 and $P_{2}$ on setup 2, based on measurements of the rise times $\left(\tau_{\mathrm{on}}\right)$ of photo-induced currents (see Fig. 4 ): we take as the conversion factor $k$ the ratio between the powers that in each setup induced a photocurrent with the same rise time. We fit the dependence of the rise times on the excitation power ( $n=4$ cells measured in setup 1 , among which 3 expressed CoChR-GFP and 1 soCoChR-GFP; $n=5$ cells measured on setup 2, among which 2 expressed CoChR-GFP and 3 soCoChR-GFP), using the expression

$$
\tau_{\mathrm{on}, i}\left(P_{i}\right)=\frac{c_{1}}{\left(P_{i}+c_{2}\right)^{2}}+c_{3}
$$

where $P_{i}$ is the photostimulation power density (with $i=1$ or 2 indicating setup 1 or setup 2 , respectively) and $c_{1}, c_{2}$ and $c_{3}$ are three free fitting parameters. For each cell, the experimental dependence of the rise time on the illumination power included at least five power values.

The conversion factor $k=P_{2} / P_{1}$ was obtained as the factor that minimized the mean square difference between the values of the curve $\tau_{\mathrm{on}, 1}\left(P_{1}\right)$ and those of the curve with the rescaled power values $\tau_{\mathrm{on}, 2}\left(k P_{1}\right)$. The value thus obtained was $k=P_{2} / P_{1} \approx 5.3$, meaning that powers used in setup 1 were about one-fifth those used in setup 2.

Diffraction efficiency corrections. Holographically generated light patterns suffer from a position-dependent diffraction efficiency ${ }^{12,56,57}$, meaning that the intensity of a holographic spot decreases with distance from the center of the field of view or from the nominal focal plane of the objective. Therefore, generation of illumination patterns with uniform intensity, crucial for the experiments in Figs. 3 , 5 and 6, required the implementation of corrective algorithms to compensate for this effect.

In the case of sequential targeting of different locations, homogenization of light distribution was achieved by generating, together with the excitation holographic spots of surface $A_{\text {spot }}$, an additional correction spot at the edge of the field of view, of surface $A_{\text {corr }}$. By adjusting the size of the correction spot we could modulate the light intensity in the excitation spot while moving the latter across the excitation field, thus achieving constant light illumination (see Supplementary Fig. 11). More precisely, at first we characterized experimentally the position-dependent diffraction efficiency, $\operatorname{DE}(x, y, z)$; then, given a sequence of $N$ illumination spots of coordinates $\left(x_{i}, y_{i}, z_{i}\right)$, we set the surface of the correction spot for each illumination site to be

$$
A_{\text {corr }_{i}}=A_{\text {spot }} \cdot\left(\frac{\mathrm{DE}\left(x_{i}, y_{i}, z_{i}\right)}{\min _{N} \mathrm{DE}}-1\right)
$$

where $\min \mathrm{DE}$ is the lowest diffraction efficiency value over the $N$ illumination sites. The correction spot was blocked at an intermediate image plane after the spatial light modulator, preventing it from reaching the sample.

For simultaneous illumination of multiple spots we used, as described by Conti et al..$^{58}$ and Hernandez et al..$^{12}$, graded input patterns to calculate with the iterative GS algorithm the corresponding phase mask (see Supplementary Fig. 11). Briefly, 
each illumination spot, the $i$ th in the ensemble of $N$, drawn in the input image for the GS algorithm was weighted with a subunitary coefficient $w_{i}$, given by

$$
w_{i}=\frac{\min _{N} \mathrm{DE}}{\mathrm{DE}\left(x_{i}, y_{i}, z_{i}\right)}
$$

This enabled us to direct more power to spots corresponding to regions with low diffraction efficiency while sending less power to the spots closer to the center of the excitation field and/or the objective focal plane.

Finally, we equalized the excitation power densities used for single-spot sequential stimulation and simultaneous multiple spot stimulation by adjusting the exit laser power.

Holographic photostimulation along neurites. Patched cells in slices were loaded with Alexa 594 hydrazide dye (15-20 $\mu \mathrm{M}$; Invitrogen) to visualize cell morphology. We imaged the patched neuron loaded with Alexa 594 with a $2 \mathrm{P}$ scanning imaging system (imaging laser at $780 \mathrm{~nm}$, setup 1$)^{59}$ or widefield illumination (at $570 \mathrm{~nm}$, setup 2). A $z$-stack of the fluorescence emission was acquired to reconstruct the $3 \mathrm{D}$ morphology of the neurites (in a range of typically $\pm 40 \mu \mathrm{m}$ ) and to target, with holographic illumination, specific $x-y$ - $z$ positions along neurites.

The photostimulation protocol consisted of sequentially displacing 10- $\mu \mathrm{m}$ diameter holographic stimulation spots from the distal end of the process toward the soma, with a step size of approximately $10 \mu \mathrm{m}$. 2P stimulation consisted of $30-\mathrm{ms}$ pulses with an illumination power density corresponding to the power threshold density required to trigger one AP when stimulating the whole soma. Practically, the power threshold density was obtained by progressively increasing the excitation power up to a value that allowed us to reliably (in three consecutive trials) trigger one AP each time.

Measurement of opsin and photo-induced AP kinetic parameters. Neurons expressing CoChR-GFP or soCoChR-GFP were patched and photostimulated with holographic spots whose diameter was between 10 and $15 \mu \mathrm{m}-$ i.e., covering the whole soma. The kinetics of the response was monitored in both current-clamp and voltage-clamp configurations. The photostimulation consisted of pulses of holographic illumination with a duration varying from $300 \mathrm{~ms}$ at low power down to a few milliseconds at high power. The reported rise time $\tau_{\text {on }}$ corresponds to the time constant of a monoexponential fit of the ascending part of the photo-induced current.

To estimate the asymptotic value of the rise time, we fit the rise time vs. power curve of each cell with equation (1). The coefficient $c_{3}$ was taken as the asymptotic value of the rise time for each cell and then averaged across cells. We considered in the average only cells in which the rise time vs. power curve had a sufficient number of experimental points $(\geq 5)$ to assure the reliability of the fit.

The AP latency was defined as the time delay between the onset of $2 \mathrm{P}$ stimulation and the peak of the photostimulated AP. The plotted values were obtained by averaging AP latencies across 5 photostimulations (separated by $30 \mathrm{~s}$ ). The duration of the photostimulation pulse was initially set to $30 \mathrm{~ms}$ for low stimulation power $\left(22 \pm 19 \mu \mathrm{W} / \mu \mathrm{m}^{2}\right)$. For high photostimulation power $\left(107 \pm 29 \mu \mathrm{W} / \mu \mathrm{m}^{2}\right)$, we decreased the duration of photostimulation to $<30 \mathrm{~ms}$ to minimize the generation of multiple spikes. The reported jitter was calculated as the s.d. of the AP latency computed across 5 consequent photostimulations. The values were extracted from the same data used to obtain the latency values.

Multiple-cell-soma holographic photostimulation in slices. Opsin-expressing cells were visualized with a $2 \mathrm{P}$ scanning imaging system (imaging laser at $\lambda=920 \mathrm{~nm}$ in setup 1) and patched. Thereafter, a $z$-stack of the GFP fluorescence emission in the volume around the patched cell was acquired to identify neighboring positive cells. The scanning imaging lasers, although inducing some photocurrents $(I=23 \pm 13 \mathrm{pA}$; imaging power $P=14 \pm 2 \mathrm{~mW}$, scanning frequency $0.74 \mathrm{~Hz} ; n=3$ soCoChR-expressing cells from 3 mice), did not induce APs during imaging. In slices expressing soCoChR-GFP, cells were clearly distinguishable, since predominantly their somata were fluorescent, with minimal neuropil fluorescence. In contrast, slices expressing CoChR-GFP presented a diffuse and homogeneous green fluorescence, in which cells could be recognizable as dark spots (spots with lower fluorescence than background).

In the volume around the patched cells, we randomly identified and selected an ensemble of neighboring fluorescent cells that we targeted with $10-14 \mu \mathrm{m}$ holographic spots. Depending on the field of view and cell distribution, we selected 5 to 8 cells. To avoid broadening of axial resolution due to the axial overlapping of multiple spots, for cells separated by an axial distance smaller than the spot FWHM (see Supplementary Fig. 8) we chose cells that were laterally shifted with respect to one another. These cells, in the vicinity of the patched cell, were sequentially stimulated with a holographic spot (30-ms illuminations, $5 \mathrm{~s}$ apart) and the generated membrane depolarizations recorded. The last cell to be photostimulated for each stimulation sequence was the patched cell. Receptor blockers were added to the ACSF solution in all experiments to block any synaptic effects (strychnine, picrotoxin, gabazine and NBQX, 1-5 $\mu \mathrm{M}$; Abcam or Tocris).

For sequential and simultaneous illumination experiments, the same power density was delivered to each spot in the pattern, thanks to our diffraction efficiency compensating algorithm (see above). Since the axial separation between the patched cell and targeted neighboring cells was $<30 \mu \mathrm{m}$, we estimated ${ }^{60}$ that the effects of scattering on the relative intensity between spots on the patched soma and on neighboring cells were less than $10 \%$ and were therefore negligible. For higher spatial separations, a uniform light distribution was obtained by adding further corrections to the intensity of each illumination spot according to axial position.

3D holographic pattern reconstruction and calibration. To reconstruct the $3 \mathrm{D}$ holographic illumination pattern in Fig. 5b and Supplementary Figs. 8 and 11, we used a dual microscope configuration as previously described ${ }^{8,9,12,52}$. Briefly, below the main upper objective we placed a second objective (NA 1.2, water immersion, $60 \times)$. While the upper objective focused the holographic pattern on a thin layer of rhodamine $6 \mathrm{G}$ (spin coated and dried on a glass coverslip), the second objective collected the fluorescence generated by the rhodamine layer, which was then recorded on a CCD camera. By changing the vertical position of the upper objective, we reconstructed the whole $x-y-z$ distribution of the holographic excitation volume.

Daily calibration of the holographic illumination system consisted in verifying the spatial alignment between the patterns of illumination and the imaging system. In setup 2 (combining 2P CGH with widefield 1P imaging), we used the holographic patterns to excite a thin fluorescent layer and checked the position of the pattern in the field by imaging the evoked fluorescence on the camera. In setup 1 (combining $2 \mathrm{P}$ CGH with $2 \mathrm{P}$ scanning imaging), we used the holographic pattern to bleach a thick fluorescent plate (Chroma, part No. 92001) and then re-imaged the bleached pattern with the $2 \mathrm{P}$ scanning laser. In this way, we obtained the exact positioning of the holographic patterns in the coordinates of the imaging system. By iteratively adjusting the coordinate system of the holographic patterns (specifically, an $x-y-z$ stretch and translation, together with a rotation in the $x-y$ plane), we could achieve a precise overlap with the imaging coordinate system. During experiments, this calibration allowed us to use fluorescent images as a reference to place with micrometric precision photostimulation spots on the structures of interest.

Image analysis: determining the fluorescence brightness from the soma to the neurites. Images for this analysis were taken at 14-18 DIV (10-14 d after transfection) from cultured neurons. The image analysis was performed in ImageJ. For each neuron we first defined the boundaries of the soma. To that end, we drew a 20 - $\mu \mathrm{m}$-diameter circle near the soma, inside which there was no apparent fluorescence from the soma or from neurites. We defined the average fluorescence in this circle as background fluorescence. We considered pixels with fluorescence intensity of at least $10 \%$ above background levels as part of the soma and processes, and we defined the boundary between soma and processes by the cell morphology. Then we drew a polygon along the defined soma boundary, measured the average fluorescence inside it and subtracted the previously calculated background value. The resulting value was considered the soma fluorescence. To measure fluorescence intensities along the neurites, we defined $1-\mu \mathrm{m}^{2}$ rectangles along the neurite that were up to $100 \mu \mathrm{m}$ away from the soma at increments of $10 \mu \mathrm{m}$. The distance between each rectangle and the soma was measured along the neurites (note well: this did not correspond to the minimum linear distance from the soma, since neurites are curved). We then defined the background value as described above for the soma. To be considered inside the neurite, we required that the pixel intensity values at the boundaries of the rectangle be at least $10 \%$ above background levels. We averaged the fluorescence intensity in each rectangle, subtracted the background, then divided it by the average soma fluorescence and plotted the resulting ratios with respect to their distances along the neurites. The ratios for each distance were averaged across neurites, and data were plotted (using Matlab) as average and s.e.m. (for CoChRGFP, $n=5$ neurites from 5 cells from 2 cultures; for soCoChR-GFP, $n=5$ neurites from 5 cells from 3 cultures; for CoChR-Na 1 .2(II-III)-GFP, $n=5$ neurites from 5 cells from 4 cultures). For the Kolmogorov-Smirnov test we verified that the dependent variable (fluorescence) was at least ordinal, that the two samples (cells expressing CoChR vs. cells expressing soCoChR) were independent and that in both cases cells were chosen randomly. Image analysis in brain slices was performed the same way; however, because of the dense labeling of cells we needed to determine the continuity of any given measured cell. Since only patched cells were labeled with Alexa 594, we verified cell continuity using the red channel and measured the fluorescence in the green (GFP) channel. This was performed for cells expressing CoChR vs. soCoChR

Sample size determination. Because the experiments here were aimed at developing a technology, rather than testing a formal scientific hypothesis, the animal numbers in the paper were forecast on the basis of past neuroengineering projects we have done, using the experience we have attained since starting the Synthetic Neurobiology group at MIT, as done by Klapoetke et al. ${ }^{19}$. This follows guidelines recommended by the $\mathrm{NIH}^{61}$ regarding "experiments based on the success or failure of a desired goal."

Data analysis. Analyzing current amplitudes and current decay time following $1 P$ photostimulation experiments. For current amplitude analysis, during 
photostimulation experiments, voltage clamp traces were recorded and the amplitudes of the current were taken directly from Clampfit (Molecular Devices) and copied into an Excel spreadsheet. For each patched cell, there was one current value. We averaged the photocurrent amplitude values across cells for each opsin targeting variant and calculated the s.e.m. ( $n=13$ neurons from 3 cultures and 13 neurons from 3 cultures for CoChR-GFP and soCoChR-GFP, respectively). We then performed a two-sided Wilcoxon rank sum test (in Matlab). Full statistics are in Supplementary Table 3. For the Wilcoxon rank sum test, we verified that we were comparing two independent categorical groups (the first group with cells expressing CoChR and the second group with cells expressing soCoChR), that the dependent variable (percentage) was ordinal and that observations of dependent variables were independent (because these were different experiments, on different neurons).

For $\tau_{\text {off }}$ analysis, during photostimulation experiments, voltage clamp traces were recorded and their current decay times $\left(\tau_{\text {off }}\right)$ were extracted from monoexponential fits in Clampfit (Molecular Devices). For each patched cell, there was one $\tau_{\text {off }}$ value. We averaged the $\tau_{\text {off }}$ values across cells for each opsin targeting variant and calculated the s.e.m. ( $n=13$ neurons from 3 cultures and 13 neurons from 3 cultures for CoChR-GFP and soCoChR-GFP). We then performed a twosided Wilcoxon rank sum test (in Matlab). Full statistics are in Supplementary Table 3. For the Wilcoxon rank sum test, we verified that we were comparing two independent categorical groups (first group with cells expressing CoChR, second group with cells expressing soCoChR), that the dependent variable (percentage) was ordinal and that the observations of dependent variables were independent (because these were different experiments, on different neurons).

Analysis procedure for DMD experiments. To find the percentage of patched cells spiking when directly photostimulated, we defined the patched cell as having an AP when its membrane voltage depolarized by at least $35 \mathrm{mV}$ upon photostimulation. For each of the 5 cells patched, we recorded the data as 1 if the patched cell yielded an AP when photostimulated and 0 if the patched cell did not yield an AP when photostimulated. We found the percentage of APs in patched cells resulting from direct stimulation by summing all instances of 1 and dividing the sum by the number of patched cells ( $n=5$ cells from 4 cultures for CoChRGFP; $n=5$ cells from 5 cultures for CoChR-KA2(1-150)-GFP)

To find the percentage of photostimulated neighboring somata yielding an AP in the patched cell, we defined the patched cell as having an AP when its membrane voltage was depolarized by at least $35 \mathrm{mV}$ upon photostimulation. The baseline was calculated as the average of the voltage values over the 100 -ms period that preceded the event. For each of the 5 cells patched, 9 cells neighboring the patched cell were photostimulated. We then counted the number of neighboring cells whose stimulation led to an AP in the patched cell and divided it by the number of photostimulated neighboring cells. This value was then averaged across the 5 patched cells ( $n=5$ cells from 4 cultures for CoChR-GFP; $n=5$ cells from 5 cultures for soCoChR-GFP). We then plotted the average percentage and s.e.m. for CoChR-GFP and soCoChR-GFP. We compared this percentage between CoChRGFP and soCoChR-GFP via a two-sided Wilcoxon rank sum test (Matlab). Before performing the Wilcoxon rank sum test, we verified that we were comparing two independent categorical groups (first group with cells expressing $\mathrm{CoChR}$, second group with cells expressing soCoChR), that the dependent variable (percentage) was ordinal and that the observations of dependent variables were independent (because these were different experiments, on different neurons).

To find the percentage of photostimulated neighboring somata yielding a depolarization in the patched cell, we defined the patched cell as having a depolarization when its membrane voltage increased from baseline by more than $0.5 \mathrm{mV}$ upon photostimulation. Baseline was calculated as the average of the voltage values over the 100 -ms period that preceded the event. For each of the 5 cells patched, 9 cells neighboring the patched cell were photostimulated. We then counted the number of neighboring cells whose stimulation led to a depolarization in the patched cell and divided it by the number of photostimulated neighboring cells. The value was averaged across the 5 patched cells $(n=5$ cells from 4 cultures for CoChR-GFP; $n=5$ cells from 5 cultures for soCoChR-GFP)). We then plotted the average percentage and s.e.m. for CoChR-GFP and soCoChR-GFP. We compared this percentage between CoChR-GFP and soCoChR-GFP by a two-sided Wilcoxon rank sum test (Matlab).

Measurement of $2 \mathrm{P}$ excitation spectrum. The wavelength dependence of the $2 \mathrm{P}$ excitation of CoChR (Supplementary Fig. 7) was measured on cultured $\mathrm{CHO}$ cells stimulated using the tunable laser in setup 1 . To cover the entire cell body, the optical path of the imaging laser was modified to underfill the objective back aperture and generate a large $2 \mathrm{P}$ Gaussian excitation $(\mathrm{FWHM}=38 \mu \mathrm{m})$ at the sample plane. Wavelength scanning was performed using photostimulation pulses of $200 \mathrm{~ms}$ at constant photon flux over the investigated wavelength range $\left(2.4 \pm 0.3 \times 10^{26}\right.$ photons s$~^{-1} \mathrm{~m}^{-2}$, defined as the time-averaged total number of photons per unit area, spatially averaged over the Gaussian spot surface). Laser pulse width is assumed to be constant across wavelengths. From the photocurrent curves, we extracted the wavelength dependence of the peak currents and of the exponential rise and decay times, which we used to deduce the normalized excitation cross-section spectrum (Supplementary Fig. 7b) using equation (13) from Chaigneau et al. ${ }^{10}$.
Modeling of the power dependence of the axial resolution of $2 P$ holographic photostimulation. The nonlinear opsin response to the illumination power can affect the effective axial resolution of photostimulation. To evaluate and model this effect, we first recorded the response of a CoChR-expressing $\mathrm{CHO}$ cell to different $2 \mathrm{P}$ holographic illumination powers (shown in the inset of Supplementary Fig. 8d). The use of cultured CHO cells, in contrast to neurons, allowed us to avoid any influence of excitation of neurites around the soma. As expected, the photoinduced peak currents at high excitation power showed saturation as power increased. In a first approximation, the curve of the normalized peak current near saturation could be fitted with an exponential curve: $I(P)=1-e^{-P / P^{\prime}}$, with $P^{\prime} \approx 0.06 \mathrm{~mW} / \mu \mathrm{m}^{2}$ $(\lambda=1,030 \mathrm{~nm}$, setup 1$)$. Second, we extracted the normalized intensity axial profile $p(z)$ of the excitation holographic spot from a Gaussian fit of the corresponding axial fluorescence profile (Supplementary Fig. 8b,c). Finally we modeled the axial profile of the photocurrent by using the expression $I(z)=1-e^{-P_{0} p(z) / P^{\prime}}$, with $P_{0}$ the nominal power density (per unit surface) at $z=0$. The results of the model are reported and compared with experimental results in Supplementary Fig. 8d,e.

A further optimization of the model would include a more precise fit of the quadratic behavior of the photocurrent at low power, far below saturation, and would also consider the convolution of the illumination profile with the exact morphology of the neuron cell body (here considered simply as a thin disk) and the spatial distribution of its axon and dendritic tree.

Analyzing photocurrent integrals under photostimulation along neurites. For each photostimulation location, 1 to 3 trials were acquired and the resulting traces were averaged. The current integral over time was calculated by integrating the current response recorded at the soma in voltage-clamp configuration from the onset of the photostimulation until the time of recovery to the initial resting value of the current. In the calculation of the integral, an offset in the current curve was introduced corresponding to the integral of the holding current at rest.

The distance from the soma was estimated on the basis of the coordinates of the photostimulation spots placed along neurites. This sequence was manually defined during the experiment and consisted of a series of $10-\mu \mathrm{m}$ spots starting from the center of the soma and moving away from it along a neurite with a step of approximately $10 \mu \mathrm{m}$ up to a maximum distance of $100 \mu \mathrm{m}$ from the soma (while taking into account the curvature of neurites). Post-experimentally, the distance between each pair of consecutive spots $d_{i}$ was defined as the Cartesian distance between the center of the consecutive spots (taking into account the $x, y$ and $z$ coordinate of each). The distance to the soma from the $i$ th spot was then calculated as

$$
\sum_{j=1}^{i-1} d_{j}
$$

The photostimulation sequence was then performed starting from the most peripheral spot on the neurites to the spot on the soma.

Current integrals over time at various neurite locations were normalized to the current integral recorded at the soma. The current integral values were then binned according to their distance from soma in intervals of $15 \mu \mathrm{m}$. Values were averaged across neurites ( 1 to 3 neurites per cell were investigated) and data plotted as mean \pm s.e.m. (Fig. 3 ). To estimate the statistical significance of the difference between CoChR-GFP and soCoChR-GFP photocurrents, we performed a twosample Bonferroni-corrected Kolmogorov-Smirnov test for each binning interval. The test was two-sided. For the Kolmogorov-Smirnov test we verified that the dependent variable (photocurrent integral) was at least ordinal, that the two samples (cells expressing CoChR vs. cells expressing soCoChR) were independent and that both samples were random (neurons and neurites to study were chosen randomly).

Results of the test are reported in Supplementary Table 4. Data were analyzed using pClamp10 software (Molecular Devices), IgorPro and Matlab (MathWorks, Inc.).

Analyzing single-and multiple-soma holographic stimulations in brain slices. For each patched cell, we counted the number of neighboring cells whose stimulation led to an AP in the patched cell, divided this number by the number of photostimulated neighboring cells and then averaged this ratio across all patched cells. Data are presented as mean \pm s.e.m. in Fig. 5. Significance was tested with the non-parametric two-sided Wilcoxon rank sum test (Matlab) for continuous variable (percentage) in Fig. 5e and the non-parametric $\chi^{2}$ test for discrete values in Fig. 5 g. For the Wilcoxon rank sum test, we verified that we were comparing two independent categorical groups (cells expressing CoChR and soCoChR), that the dependent variable (percentage) was ordinal and that observations of dependent variables were independent (since obtained on different experiments and different neurons). For the $\chi^{2}$ test, we verified that variables were mutually exclusive and that the studied groups were independent (cells expressing CoChR and soCoChR).

For simultaneous stimulation experiments, we calculated the percentage of patched cells firing a single AP or multiple APs when their neighbors were simultaneously stimulated. Illumination patterns were composed of 5 to 8 holographic spots. The results were averaged across the patched cells. 
Connectivity experiments were performed by sequentially photostimulating presynaptic cells. The whole photostimulation sequence was repeated three times. The postsynaptic traces from the three trials were averaged for analysis and for the traces reported in the figures. Whenever stimulation of presynaptic cell elicited a current $\left(I_{\mathrm{TOT}}\right)$ in the patched cell, we defined the artifactual component, $I_{\mathrm{ART}}$, as the residual current left after application of synaptic blockers. The PSC component was then calculated as $\mathrm{PSC}=I_{\mathrm{TOT}}-I_{\mathrm{ART}}$. The ratio PSC $/ I_{\mathrm{ART}}$ was used to compare connectivity experiments performed using soCoChR-GFP and CoChR-GFP. Data are presented as mean \pm s.e.m. in Fig. 6. Data were analyzed using pClamp10 software (Molecular Devices), IgorPro and R-studio.

Excluding data points. For recording in slices, data points (singular trials) were excluded if the recording was unstable, meaning the baseline potential changed by more than $5 \mathrm{mV}$ during the recording. Cells were excluded if a gigaohm seal was lost or a high leak current appeared.

For recording in culture, data points (cells) were excluded if we could not establish a gigaohm seal.

Statistics. For comparison of GFP brightness vs. position along the neurite between constructs, two-sample Kolmogorov-Smirnov (K-S) tests with Bonferroni correction were performed. For comparing spike probability vs. irradiance, Bonferroni-corrected Wilcoxon rank sum tests were used. For comparisons of normalized integrated photocurrent along neurites, two-sample K-S tests with Bonferroni correction were used. For comparing of the average distances between patched cells and photostimulated cells, Wilcoxon rank sum tests were performed. For comparing single and multiple spike probabilities, the $\chi^{2}$ test was used. Wilcoxon rank sum tests were used for comparison of PSC and $I_{\mathrm{ART}}$ currents and for comparison of the PSC/I $I_{\mathrm{ART}}$ ratios. Data collection and analysis were not performed blind to the conditions of the experiments. Animals and cultures were randomly assigned to the different experimental groups. Information about the experimental design and statistics are given in the Life Sciences Reporting Summary. Normality and equal variances were not assumed, and therefore all tests were non-parametric (K-S test, $\chi^{2}$ test, Wilcoxon rank sum test).

Accession codes. GenBank: SoCoChR-GFP, MF795583; KA2(1-150), MF795584.

Life Sciences Reporting Summary. Further information on experimental design is available in the Life Sciences Reporting Summary.
Data availability. All relevant data are available from the authors upon reasonable request. Sequences are available in the Supplementary Note. Clones will be made available through the nonprofit DNA distributor Addgene, as well as the University of North Carolina and University of Pennsylvania viral cores.

\section{References}

47. Jiang, M. \& Chen, G. High $\mathrm{Ca}^{2+}$-phosphate transfection efficiency in low-density neuronal cultures. Nat. Protoc. 1, 695-700 (2006).

48. Chow, B. Y. et al. High-performance genetically targetable optical neural silencing by light-driven proton pumps. Nature 463, 98-102 (2010).

49. Ma, D. et al. Role of ER export signals in controlling surface potassium channel numbers. Science 291, 316-319 (2001).

50. Hofherr, A., Fakler, B. \& Klöcker, N. Selective Golgi export of Kir2.1 controls the stoichiometry of functional Kir2.x channel heteromers. J. Cell Sci. 118, 1935-1943 (2005).

51. Ducros, M. et al. Efficient large core fiber-based detection for multi-channel two-photon fluorescence microscopy and spectral unmixing. J. Neurosci. Methods 198, 172-180 (2011).

52. Lutz, C. et al. Holographic photolysis of caged neurotransmitters. Nat. Methods 5, 821-827 (2008).

53. Gerchberg, R. \& Saxton, W. A practical algorithm for the determination of the phase from image and diffraction plane pictures. Optik 35, 237 (1972).

54. Haist, T., Schönleber, M. \& Tiziani, H. J. Computer-generated holograms from 3D-objects written on twisted-nematic liquid crystal displays. Opt. Commun. 140, 299-308 (1997).

55. Hernandez, O., Guillon, M., Papagiakoumou, E. \& Emiliani, V. Zero-order suppression for two-photon holographic excitation. Opt. Lett. 39, 5953-5956 (2014).

56. Golan, L., Reutsky, I., Farah, N. \& Shoham, S. Design and characteristics of holographic neural photo-stimulation systems. J. Neural Eng. 6, 066004 (2009).

57. Yang, S. et al. Three-dimensional holographic photostimulation of the dendritic arbor. J. Neural Eng. 8, 046002 (2011).

58. Conti, R., Assayag, O., de Sars, V., Guillon, M. \& Emiliani, V. Computer generated holography with intensity-graded patterns. Front. Cell. Neurosci. 10, 236 (2016).

59. Mütze, J. et al. Excitation spectra and brightness optimization of two-photon excited probes. Biophys. J. 102, 934-944 (2012).

60. Horton, N. G. et al. In vivo three-photon microscopy of subcortical structures within an intact mouse brain. Nat. Photonics 7, 205-209 (2013).

61. Dell, R. B., Holleran, S. \& Ramakrishnan, R. Sample size determination. ILAR J. 43, 207-213 (2002). 


\section{natureresearch}

Corresponding author(s): Ed Boyden and Valentina Emiliani

Initial submission

Revised version

$\bigotimes$ Final submission

\section{Life Sciences Reporting Summary}

Nature Research wishes to improve the reproducibility of the work that we publish. This form is intended for publication with all accepted life science papers and provides structure for consistency and transparency in reporting. Every life science submission will use this form; some list items might not apply to an individual manuscript, but all fields must be completed for clarity.

For further information on the points included in this form, see Reporting Life Sciences Research. For further information on Nature Research policies, including our data availability policy, see Authors \& Referees and the Editorial Policy Checklist.

\section{- Experimental design}

\section{Sample size}

Describe how sample size was determined.

2. Data exclusions

Describe any data exclusions.

\section{Replication}

Describe whether the experimental findings were reliably reproduced.

\section{Randomization}

Describe how samples/organisms/participants were allocated into experimental groups.

\section{Blinding}

Describe whether the investigators were blinded to group allocation during data collection and/or analysis.
The explanation for sample size is given in the manuscript, under "Sample size determination" (p. 43).

Because the experiments here were aimed at developing a technology, rather than testing a formal scientific hypothesis, the animal numbers in the paper were forecasted based upon past neuroengineering projects we have done, using the experience we have attained since starting the Synthetic Neurobiology group at MIT, similar to Klapoetke et al19. This follows guidelines recommended by the NIH63 regarding "experiments based on the success or failure of a desired goal."

For recording in slices, data points (singular trials) were excluded if the recording was unstable, meaning the baseline potential changed by more than $5 \mathrm{mV}$ during the recording. Cells were excluded if a gigaohm seal was lost or a high leak current appeared.

For every experiment we conducted, we repeated it several time and then conducted a statistical test to check for an experimental effect. Reliability led to statistical significance.

Animals and cultures were randomly assigned to the different experimental groups.

It appears in the methods section, paragraph " Randomization".

Note: all studies involving animals and/or human research participants must disclose whether blinding and randomization were used. 


\section{Statistical parameters}

For all figures and tables that use statistical methods, confirm that the following items are present in relevant figure legends (or in the Methods section if additional space is needed).

$\mathrm{n} / \mathrm{a} \mid$ Confirmed

The exact sample size $(n)$ for each experimental group/condition, given as a discrete number and unit of measurement (animals, litters, cultures, etc.)

$\triangle$ A description of how samples were collected, noting whether measurements were taken from distinct samples or whether the same sample was measured repeatedly

$\bigotimes$ A statement indicating how many times each experiment was replicated

The statistical test(s) used and whether they are one- or two-sided (note: only common tests should be described solely by name; more complex techniques should be described in the Methods section)

$\bigotimes$ A description of any assumptions or corrections, such as an adjustment for multiple comparisons

$\bigotimes$ The test results (e.g. $P$ values) given as exact values whenever possible and with confidence intervals noted

Х A clear description of statistics including central tendency (e.g. median, mean) and variation (e.g. standard deviation, interquartile range) Clearly defined error bars

See the web collection on statistics for biologists for further resources and guidance.

\section{- Software}

Policy information about availability of computer code

\section{Software}

Describe the software used to analyze the data in this study.

Software used: Matlab, origin8, IgorPro, pClamp10, Excel.

For manuscripts utilizing custom algorithms or software that are central to the paper but not yet described in the published literature, software must be made available to editors and reviewers upon request. We strongly encourage code deposition in a community repository (e.g. GitHub). Nature Methods guidance for providing algorithms and software for publication provides further information on this topic.

\section{- Materials and reagents}

Policy information about availability of materials

\section{Materials availability}

Indicate whether there are restrictions on availability of unique materials or if these materials are only available for distribution by a for-profit company.

\section{Antibodies}

Describe the antibodies used and how they were validated for use in the system under study (i.e. assay and species).

\section{Eukaryotic cell lines}

a. State the source of each eukaryotic cell line used.

b. Describe the method of cell line authentication used.

c. Report whether the cell lines were tested for mycoplasma contamination.

d. If any of the cell lines used are listed in the database of commonly misidentified cell lines maintained by ICLAC, provide a scientific rationale for their use.
We provided a Data availability statement (p.14-15): "All relevant data are available from the authors. Sequences are available in this manuscript under Supplementary information. Clones will be made available through the nonprofit DNA distributor Addgene, as well as the UNC and UPenn Viral cores".

No antibodies were used in our study.

Chinese hamster ovary $(\mathrm{CHO})$ ordered from Sigma-Aldrich, subclones of the parental CHO cell line originated by Puck in 1957 (The Journal of experimental medicine, 108, (1958-12-1)).

Not known; presumably standard Sigma-Aldrich procedures were followed. Cells lot number 100001

Cell lines were tested with Hoechst method.

$\mathrm{CHO}$ cells are not in the list. 
Policy information about studies involving animals; when reporting animal research, follow the ARRIVE guidelines

\section{Description of research animals}

Provide details on animals and/or animal-derived materials used in the study.
Species: the species of animals were reported in in the Methods, under "Viral injections and whole-cell electrophysiology in brain slices" (p.33) and "Primary neuron culture, transfection and transduction " (p.29).

Strain: the strain of animals strains were well-characterized mice strains appearing in multiple publications from multiple labs.

Sex: for slice experiments we used male mice, and mentioned it under "Viral injections and whole-cell electrophysiology in brain slices".

For cultures, we do not know the sex of the mice used for the experiments.

Age: reported in the Methods, under "Viral injections and whole-cell electrophysiology in brain slices" and "Primary neuron culture, transfection and transduction ".

Policy information about studies involving human research participants

\section{Description of human research participants}

Describe the covariate-relevant population characteristics of the human research participants.
N/A 